\title{
Una alternativa contra la hipertrofia de la justicia constitucional chilena*
}

\author{
A choice for the hypertrophy \\ of the chilean constitutional review
}

SUMARIO

I. ¿Un diagnóstico común? II. Rodeo kelsenita. III. Problematizando a Kelsen. IV. Fundamentando un constitucionalismo débil y dialógico. V. Modelando el diálogo entre cortes y parlamentos. 1. El modelo canadiense. 2. Los modelos británico y neozelandés. 3. Modelos puramente teorizados. VI. Perspectivas.

\section{RESUMEN}

Este artículo sugiere que se advierte un consenso en torno a la necesidad de recortar competencias del tribunal constitucional chileno, pero que la reflexión al respecto es aún poco desarrollada. Por eso, agrega que la justificación general de la jurisdicción constitucional tiene que argumentar que ella hace algo -velar epistémicamente por los resultados del proceso democrático-que no hacen ni el parlamento ni el gobierno, y que una justificación especial de la misma podría conducir a alguna forma de constitucionalismo débil y dialógico en la senda del nuevo modelo constitucional de la Commonwealth.

\section{PALABRAS CLAVE}

Control judicial de constitucionalidad, democracia, justificación epistémica, constitucionalismo débil.

* Escuela de Derecho, Pontificia Universidad Católica de Valparaíso, Chile. Contacto: enzo.solari@ucv.cl

El autor agradece los comentarios y las críticas que a versiones preliminares de este texto le formularan tanto los participantes del Coloquio de Filosofía del Derecho y Derecho Penal que se reúne regularmente en la Escuela de Derecho de la Pontificia Universidad Católica de Valparaíso, como los de las Jornadas de Filosofía del Derecho de la Sociedad Chilena de Filosofía Jurídica y Social realizadas el año 2014, y sus ayudantes Juan Ignacio Fuenzalida y Nelson Rosas.

** Recibido el: 6 de agosto de 2015, aprobado el: 12 de octubre de 2015.

Para citar el artículo: E. SOLARI, Una alternativa contra la hipertrofia de la justicia constitucional chilena, Derecho del Estado n. ${ }^{\circ}$ 35, Universidad Externado de Colombia, juliodiciembre de 2015, pp. 201-241. DOI: http://dx.doi.org/10.18601/01229893.n35.08 


\section{ABSTRACT}

This paper posits that there is a growing consensus on the need to reduce the powers of the Chilean constitutional court, while conceding that this issue has received little treatment to date. The general purpose of constitutional justice would be to do something particular, different from what government or congress does; namely to look out epistemically for the results of the democratic process. And a specific and contextualized defense of constitutional justice could lead to a form of weak and dialogic constitutionalism along the lines of the new Commonwealth model of constitutionalism.

\section{KEYWORDS}

Judicial review, democracy, epistemic justification, weak constitutionalism.

La tradicional ingenuidad del constitucionalismo chileno y del propio Tribunal Constitucional de Chile (= TC), tan visible cuando se la pone en comparación con los estándares y las actitudes de otras dogmáticas y tribunales que sí han discutido (e imaginado modos institucionalizados de encarar) el conflicto que plantea el principio democrático al mecanismo del control judicial de constitucionalidad cuando se ejecuta abstractamente, parece estar declinando. Esto, que ya he descrito en otro lugar ${ }^{1}$, refleja una tendencia positiva: tiende a imponerse entre nosotros una crítica se diría que políticamente transversal a la hipertrofia de la judicatura constitucional. No obstante lo cual la discusión en Chile acerca del control judicial de constitucionalidad (repito: in abstracto) sigue siendo todavía escasa, abstracta y polarizada, pues o bien se argumenta simplemente en favor de la legitimidad de la judicatura constitucional (acudiéndose incluso al decisivo papel histórico que desempeñara ella durante el último lustro de la dictadura pinochetista), o bien se arguye en su contra (destacándose -no siempre con suficiente complejidad- su innecesario carácter para-legislativo, contramayoritario, que aun haría recomendable su supresión).

\section{I. ¿UN DIAGNÓSTICO COMÚN?}

Como decía, ya se detecta cierta coincidencia en diagnosticar que el TC está institucionalmente diseñado de unas maneras que hacen que él intervenga mucho más allá de la cuenta en el proceso democrático, precisamente por

1 E. SOlari. Un constitucionalismo inocuo. Estudios Constitucionales 10/2, 2012, pp. 455-510. 
ser un órgano que dispone de 'la última palabra' institucionalmente hablando (vale decir, dictando la regla jurídica de cierre) cuando interpreta y decide acerca de la significación de las normas constitucionales y de los derechos fundamentales que ellas protegen. Esta idea, según la cual el TC dispone de un poder excesivo, responde tanto a su configuración institucional como a su propia autocomprensión. Como se sabe, el actual TC difiere por su mayor poder del establecido desde 1970 en la Constitución chilena de 1925. Este último resolvía las cuestiones sobre constitucionalidad suscitadas durante la tramitación de los proyectos de ley y de los tratados sometidos a la aprobación del Congreso (art. 78 b) y contra sus resoluciones no procedía recurso alguno (art. 78 c). Hoy, y sobre todo luego de la reforma del año 2005 a la Constitución chilena de 1980, el TC ejerce una amplísimo control de constitucionalidad, pues controla las leyes que interpreten algún precepto de la Constitución, las leyes orgánicas constitucionales y las normas de un tratado que versen sobre materias propias de estas últimas -antes de su promulgación-, también resuelve las cuestiones sobre constitucionalidad que se susciten durante la tramitación de los proyectos de ley o de reforma constitucional y de los tratados sometidos a la aprobación del Congreso (casos en los que "el Tribunal solo podrá conocer de la materia a requerimiento del Presidente de la República, de cualquiera de las Cámaras o de una cuarta parte de sus miembros en ejercicio"), así como las cuestiones de constitucionalidad de un decreto con fuerza de ley, la inaplicabilidad por inconstitucionalidad de un precepto legal en cualquier gestión que se siga ante un tribunal ordinario o especial, y la constitucionalidad de los decretos supremos (art. 93) ${ }^{2}$. Y en cuanto a la autocomprensión que ha llegado a desarrollar acerca de su papel institucional, el TC ha dicho, como es fama, que su propia voluntad sustituye la de los parlamentarios o la del Presidente de la República -abusando así de ideas de Chiovenda, las que en realidad no permiten apoyar nada semejante, sino solamente que el juez sustituye "la voluntad contingente del demandado [...] por la voluntad concreta de la ley", una cosa toto caelo diferente ${ }^{3}$.

2 La actuación del TC a requerimiento de parlamentarios ha sido, en los hechos, la vía donde más nítidamente se exhibe la actuación políticamente relevante del TC-medida por la frecuencia de sus declaraciones de inconstitucionalidad-, en comparación con las demás vías, en las que su actuación política ha sido más bien marginal: ver ROYCE CARROLL y LYDIA TIEDE. Judicial Behavior on the Chilean Constitutional Tribunal. Journal of Empirical Legal Studies, 8/4, 2011, pp. 866-867 y 869-874.

3 Se trata, como se sabe, de la sentencia Rol 591, c. 9. La cita a propósito de Chiovenda procede del comentario de Fernando Atria. Veinte años después. Neoliberalismo con rostro humano. Santiago de Chile, Catalonia, 2013a, p. 194. En todo caso, el procesalismo contemporáneo no siempre mira con buenos ojos estas ideas de Chiovenda: ver LUIZ MARINONI, ÁlVARO PÉREZ 
El problema, podría decirse, es que por aquella configuración institucional y por esta autocomprensión de su labor el TC solo está en condiciones de realizar un tipo de interpretación constitucional que se aproxima a una de las variantes clásicas de la misma -la más expansiva y activista- que identificaba Ely en su clásico libro. En efecto, y aunque las apariencias parezcan decir lo contrario, el TC no puede ni pretende ceñirse al 'interpretativismo (= interpretivism) o literalismo', que es aquella posición según la cual los jueces constitucionales solo deben aplicar las normas explícitamente establecidas en la constitución más las claramente implícitas en estas. Ejemplos de este noliteralismo son tanto la comprensión neoliberal de la 'constitución económica' que -ha sostenido el TC- estaría incluida en la Constitución vigente ${ }^{4}$, como la acogida más reciente - por parte del mismo TC, en un vuelco espectacular- de la idea de derechos sociales ${ }^{5}$. Todo esto es lo que permite decir, por otro lado,

y RAÚl NúÑEZ. Fundamentos del proceso civil. Hacia una teoría de la adjudicación. Santiago de Chile, Abeledo Perrot, 2010, pp. 13-15 y 90-91.

4 Entre otros fallos del TC que marchan en estas direcciones, ver Rol 146-1992 (inconstitucionalidad del Decreto supremo del Ministerio de Obras Públicas n. ${ }^{\circ} 357$, publicado en el Diario Oficial de 19 de febrero de 1992, que prohibía la colocación de carteles, avisos de propaganda o cualquiera otra forma de anuncios comerciales en los caminos públicos del país ) y Rol 534-2006 (inconstitucionalidad del art. 183 ter de un proyecto de ley que, regulando el trabajo en régimen de subcontratación, introducía un nuevo concepto de empresa en el actual art. $3 .{ }^{\circ}$ del Código del Trabajo, eliminando de tal concepto la exigencia de que la empresa haya de tener una "identidad legal determinada"). Una elaboración doctrinal, particularmente influyente en Chile y que permite dar respaldo teórico a fallos como los mencionados, es la de A. Fermandois. Derecho Constitucional Económico. T 1, Garantías económicas, doctrina y jurisprudencia. T. 2, Regulación, tributos y propiedad. Santiago de Chile, Universidad Católica de Chile, 22006/2010. Una crítica a dicha concepción es la de CH. VIERA. Libre iniciativa económica y Estado social. Análisis al estatuto de la libertad de empresa en la Constitución chilena. Santiago de Chile, Legal Publishing, 2013, sobre todo el cap. IV respecto de la Constitución económica chilena (pp. 181-239), que aborda críticamente la argumentación de Fermandois por su peculiar comprensión tanto del principio de subsidiariedad (pp. 196-216) como de la idea de orden público económico (pp. 216-239). Ver también Atria. Neoliberalismo, cit., pp. 64 y 193-196.

5 Tales fallos recientes son sobre todo el Rol 976-2008 (inconstitucionalidad del art. 38 ter de la Ley de Isapres por vulnerar los artículos constitucionales 19 n. ${ }^{\circ} 2$-discriminación arbitraria-y n. ${ }^{\circ} 9$-respecto de la libertad de elección de sistema de salud-) y el Rol 1710-2010 (inconstitucionalidad de los numerales 1, 2, 3 y 4 del inciso $3 .^{\circ}$ del artículo 38 ter de la Ley de Isapres fundada en la afectación de derechos fundamentales como el de igualdad ante la ley, el de protección de la salud y el derecho a la seguridad social). Sobre esto, que merecería una consideración detallada que aquí no aportaré, véanse algunos comentarios: en cuanto al primer fallo, los T. JORDÁn, “Algunos comentarios a la sentencia del TC n. 9 976/2008”, J. MARTínEZ ESTAY. Los derechos sociales: una reflexión a propósito de la sentencia rol 976 del tC, y CH. VIERA. La emergencia de los derechos sociales en el sistema constitucional chileno. Comentario de la sentencia del TC relativa a la Ley de Isapres: de la mera expectativa al derecho en forma, todos en Nomos. Revista de Derecho de la Universidad Viña del Mar, 2, 2008, pp. 263-274, 275-290 y 291-305, respectivamente, así como, en cuanto al segundo, el de P. MARSHALL. Tabla 
que el TC sí ha podido y querido adoptar una suerte de "no interpretativismo (= noninterpretivism) o liberalismo interpretativo', que es aquella posición según la cual los jueces constitucionales no solo deben aplicar las normas constitucionales explícitas e implícitas, sino también ciertas normas que no pueden ser descubiertas dentro del documento constitucional -y que, si en teoría podrían ser las de la moral popular, de una teoría de la justicia o de alguna concepción de la democracia, en nuestro caso, como dije, han sido económicamente neoliberales como últimamente cuasi socialdemócratas ${ }^{6}$.

La crítica chilena a la hipertrofia del control judicial abstracto de constitucionalidad la ha protagonizado Fernando Atria, quien ha venido sosteniendo que, pese a su nombre, el TC no es por su función un órgano jurisdiccional, sino una tercera cámara que interviene el proceso político neutralizando la agencia política democrática. Por ello ha abogado, muy públicamente, sea (en el mejor escenario posible) por su supresión, sea (en un escenario más restringido y minimalista) por la desaparición de sus funciones de control preventivo y abstracto $^{7}$. Desde la derecha jurídica, José F. García ha discrepado de Atria, reconociendo que el activismo constitucional es indeseable, pero agregando que los jueces constitucionales chilenos no han sido tan interventores del proceso democrático. García ha recordado que tales jueces, sin ser militantes partisanos, pertenecen por partes iguales a las dos tradiciones políticas dominantes en Chile (cinco a la liberal-conservadora, cinco a la progresista). Pero ha concedido un punto decisivo: que así como la Constitución chilena incluye mecanismos contramayoritarios excesivos, así también "parece haber consenso en la poca eficacia del control preventivo obligatorio, $[. .$.$] de que en materia$ de nombramientos, la política esté sobre la mesa y no en la opacidad, y [de] que existan procesos transparentes y exigentes de escrutinio de las credenciales de los candidatos al TC", destacando especialmente la necesidad de diseñar "fórmulas moderadas de revisión judicial [...] sobre bases procedimentales, más que sustantivas", todo esto en línea con las ideas de Ely y dentro de una cierta defensa de lo que denomina 'minimalismo constitucional's.

de factores de la Ley de Isapres y derechos fundamentales (Tribunal Constitucional). Revista de Derecho. Universidad Austral de Valdivia, 23/2, 2010, pp. 247-264.

6 John Hart Ely. Democracy and Distrust. A Theory of Judicial Review. Cambridge (Mass.) y London, Harvard University Press, 1980, p. 1. Todo sea dicho: ElY distinguía al no interpretativismo tanto del activismo como de la autorrestricción (self-restraint). ElY, Democracy, p. $1, \mathrm{n} . *$.

7 Ver F. AtRiA. El TC como tercera cámara. La Segunda (9.09.2008), y La Constitución tramposa. Santiago de Chile, Lom, 2013b. Para un resumen, ver SolARI. Constitucionalismo, cit., pp. 488-490.

8 Ver J. F. GARCÍA. Minimalismo e incrementalismo constitucional. Revista Chilena de Derecho, 41/1, 2014, pp. 294-295, y TC en momentos de cambio. La Tercera (14.08.2014). 
Pues bien pese a este consenso contrario tanto a un TC cuya configuración institucional lo capacita para intervenir y aun entorpecer el proceso político, y que además ha caracterizado su propia identidad bajo moldes exagerados y proactivistas -como un cautelador de los valores ínsitos en una constitución cuya supremacía tendría que defender a toda costa-, yo diría que lo que en Chile aún se echa en falta es una reflexión todavía más rigurosa sobre (a) la justificación general de la judicial review, así como sobre (b) la justificación especial de la misma mediante la ponderación de diversas modelaciones institucionales, particularmente de aquellas en las cuales (b.1) se mantiene un órgano que ejecute control en abstracto de constitucionalidad, (b.2) sin que tal control despoje al parlamento de tomar las decisiones políticas últimas en materias de derechos y respecto de los alcances de las normas constitucionales, pero (b.3) obligando a un diálogo deliberado en el que tanto el órgano contralor como el controlado -el parlamentario y el administrativo- tengan que justificar explícita y muy públicamente sus argumentos contrarios o favorables a la constitucionalidad de la legislación -y de sus normas administrativas.

\section{RODEO KELSENITA}

Para entender mejor esta diferencia de perspectiva resulta iluminador recordar los trazos básicos del modelo que creara Kelsen -y que es paradigmático para el diseño y la práctica del propio TC. Según esa perspectiva ya tradicional, el tribunal constitucional realiza un control concentrado -tanto abstracto como concreto- de constitucionalidad de leyes y de otras normas y actos jurídicos. Kelsen decía que una tal idea no es otra que la de entregar a un tribunal la tarea de defender la constitución contra aquellas violaciones que la contradicen inmediatamente por acción u omisión ${ }^{9}$. Sin una justicia constitucional, creía Kelsen, la constitución no sería plenamente obligatoria, sino "un deseo sin fuerza obligatoria [un voeu sans force obligatoire]", quedando entonces las minorías desprotegidas ante la mayoría ${ }^{10}$. El constitucional habría de ser un tribunal independiente y que debe decidir, a través de un procedimiento contencioso, acerca de la constitucionalidad de actos del parlamento que hayan sido cuestionados, así como también de actos del gobierno, anulando

9 Ver H. KELSEN. ¿Quién debe ser el defensor de la Constitución? (1931). En: La polémica Schmitt/Kelsen sobre la justicia constitucional. Trad. M. SÁNCHEZ y R. BRIE. Madrid, Tecnos, 2009, pp. 291-292.

10 Ver H. KelSEN. La garantie juridictionnelle de la Constitution (La Justice constitutionnelle). Revue de Droit Publique et de la Science Politique en France et a l'Étranger, 35, 1928, pp.pp. 250 y 253. 
tales actos si incurren en inconstitucionalidad y "eventualmente juzgando a determinados organismos imputados, acerca de la responsabilidad imputada" 11 .

Según Kelsen, una línea argumentativa como la de "si este órgano es un 'Tribunal' y si su función es auténtica 'Justicia'”, plantearía un problema totalmente "banal" 12 . Porque, se diga a ello que sí o que no, en todo caso nada se diría aún "a favor o en contra de la transferencia de la función señalada a un órgano colegiado, a cuyos miembros - convocados de alguna manera- les sea garantizada la plena independencia" tanto frente al gobierno como frente al parlamento ${ }^{13}$. Es decir, sea o no sea un órgano judicial, esto no es algo que vuelva imposible o irrealizable, inconveniente o indeseable al tribunal constitucional como institución ${ }^{14}$. Este contraargumento kelseniano tiene destinatario conocido: Carl Schmitt. Por eso dice: si Schmitt reconoce que el control que efectúa la Corte Suprema de Estados Unidos hace de ella un defensor de la Constitución norteamericana, no se ve cómo, sin embargo, se le pueda negar este carácter a los tribunales civiles, penales y administrativos que ejercen un control de constitucionalidad material y concreto ${ }^{15}$. Schmitt, al negar carácter de defensores de la constitución a los tribunales de justicia, realizaría "una afirmación puramente terminológica" ${ }^{6}$. Es cierto, según Kelsen, que el órgano controlador de constitucionalidad, puesto que "anular una ley es dictar una norma general" y crear normas generales -no individuales- es propio del legislador, realiza una función legislativa, no jurisdiccional. En este sentido un tribunal constitucional puede ser un legislador negativo, sin dejar por ello de realizar una auténtica función jurisdiccional ${ }^{17}$. Empero, cuando realiza control concreto de constitucionalidad y no aplica una ley en un caso por ser inconstitucional, este tribunal se sitúa en una zona intermedia entre la legislación -productora de normas generales- y la jurisdicción -productora de normas individuales-.

Kelsen creía que un tribunal constitucional es perfectamente coherente con la división de poderes -más que con una total separación de los mismos-, gracias a la cual estos pueden controlarse recíprocamente ${ }^{18}$. Su justificación, decía, radica en que, siendo posible la violación de la constitución por parte

11 Kelsen, Defensor, p. 302.

12 Kelsen, Defensor, p. 302.

13 Kelsen, Defensor, p. 302.

14 KeLSEN, Defensor, pp. 302-304.

15 Kelsen, Defensor, p. 303.

16 Kelsen, Defensor, p. 304.

17 Ver Kelsen, Garantie, pp. 224-226.

18 Ver Kelsen, Defensor, pp. 323-324 n. 11; Garantie, ver p. 225. 
del parlamento y/o del gobierno, es preciso que otro órgano independiente -porque nadie es ni puede ser juez en su propia causa- vele por la integridad constitucional ${ }^{19}$. La objeción democrática contra un tribunal constitucional, ya enarbolada por Schmitt, sería pues derrotable, bastando para ello que sus miembros fuesen electos ${ }^{20}$. Un tribunal constitucional, por lo demás, puede ser importante en la medida en que refleje el pluralismo social y político en su forma de proceder, esto es, si el procedimiento al que se ciñe es contencioso y permite la concurrencia pública de argumentos en pro y en contra de la constitucionalidad de una ley o de un acto administrativo. Tal 'forma judicial' -la discusión pública de intereses que se oponen- es esencial para Kelsen ${ }^{21}$.

Kelsen, como se sabe, pensaba que los jueces crean derecho y que, sobre todo cuando operan con importantes márgenes de discrecionalidad, actúan políticamente 22 . Contra Schmitt, que cree que "las cuestiones 'políticas' no son justiciables", Kelsen decía que la función de un tribunal constitucional es política como la de un tribunal ordinario, aunque en una medida mayor. Yo diría que esto es impecable. En cambio, problemática es esta otra conclusión kelseniana: que aunque no sea un tribunal, la función de un tribunal constitucional podría ser efectivamente jurisdiccional, "y mucho menos que esta función no pueda ser transferida a un órgano dotado de independencia judicial" ${ }^{23}$. Sea de esto último lo que fuere, Kelsen afirmaba que Schmitt no precisó su concepto de jurisdicción y que no advirtió la analogía funcional entre un tribunal constitucional y los tribunales ordinarios, todos los cuales suelen enfrentarse al problema de leyes de contenido dudoso: "generalmente la jurisdicción comienza una vez que las normas, en cuanto a su contenido, se tornan dudosas y discutibles, pues de otro modo se trataría solo de controversias sobre hechos y nunca propiamente de controversias sobre el "derecho"" 24 . Es cierto que podría ser preferible encomendar la defensa constitucional a un gobierno o a un parlamento, mas no porque un tribunal constitucional no pueda impartir justicia determinando el contenido "de una ley constitucional dudosa" 25 . Tampoco, según Kelsen, es admisible que un tribunal constitucio-

19 Ver Kelsen, Defensor, pp. 339-340; la misma idea aparece ya en Garantie, pp. 223 y 227.

20 Ver Kelsen, Defensor, pp. 356-357.

21 Kelsen, Defensor, pp. 325-328; ver en general pp. 328-352.

22 Ver Kelsen, Defensor, pp. 305-308.

23 Kelsen, Defensor, p. 308.

24 Ver Kelsen, Defensor, p. 310.

25 Ver Kelsen, Defensor, p. 311. 
nal no haga lo que los demás tribunales: subsunciones de hechos concretos ${ }^{26}$. Porque un tribunal constitucional sí que subsume: "el 'hecho concreto', que en la decisión acerca de la constitucionalidad de una ley es subsumido bajo la norma constitucional, no es una norma -hecho concreto y norma son dos nociones diferentes-, sino que es la producción [eventualmente inconstitucional] de una norma" 27 .

Hay una condición, agregaba Kelsen, para que este 'legislador negativo' actúe de manera auténticamente judicial. Y es que las cláusulas constitucionales tendrían que ser estrictas y no valorativas ${ }^{28}$. Pues a un tribunal constitucional, como en general a cualquier otro tribunal, debería limitársele el carácter político de su función y así su poder, limitando tanto como sea posible "el espacio de la libre discrecionalidad que las leyes conceden en su aplicación" 29. Las normas constitucionales, afirmaba por eso Kelsen, "no deben ser formuladas en términos demasiado generales, no deben emplear terminología difusa, como 'libertad', 'igualdad', 'justicia', etc.”, porque entonces sí que puede producirse un indeseable traslado de poder desde el parlamento a una institución no representativa ${ }^{30}$. La diferencia entre concepto y concepción de Hart ya se vislumbraba en Kelsen, con su diferenciación entre fórmulas ideales o de principio (justicia, igualdad, etc.) y las distintas concepciones que acerca de las mismas pueden desarrollarse discrecional e ideológicamente ${ }^{31}$. En las normas constitucionales, decía Kelsen, tales fórmulas desprovistas de significación precisa son "extremadamente" peligrosas ${ }^{32}$. Puesto que podría ocurrir que un tribunal constitucional aplicara una fórmula de justicia de una manera ideológica contrapuesta a la ideología de la mayoría de la población representada en el parlamento, cosa que sería "absolutamente inadmisible" 33 . Lo cual supondría un desplazamiento del poder democrático "no querido por la constitución y contraindicado políticamente" ${ }^{34}$. De ahí, en fin, concluía Kelsen, la necesidad de que la fraseología constitucional, también tratándose de derechos, sea formulada tan precisamente como sea posible ${ }^{35}$.

26 Ver Kelsen, Defensor, p. 312.

27 Ver Kelsen, Defensor, pp. 312-313.

28 Ver Kelsen, Defensor, pp. 320-325, esp. n. 10.

29 Ver Kelsen, Defensor, p. 320.

30 Ver Kelsen, Defensor, p. 320.

31 Ver Kelsen, Defensor, pp. 320-322 n. 10.

32 Ver Kelsen, Garantie, pp. 240-241.

33 Ver Kelsen, Defensor, p. 322 n. 10.

34 Ver Kelsen, Defensor, p. 323 n. 10.

35 Ver Kelsen, Defensor, p. 323 n. 10. 


\section{PROBLEMATIZANDO A KELSEN}

Esto es, pues, lo que Kelsen ha aportado a la discusión contemporánea acerca de la variante concentrada del judicial review que él mismo elaboró: una definición del órgano defensor constitucional como híbrido de juzgador y legislador (es decir, la concesión de que el tribunal constitucional podría no ser propia o exclusivamente un tribunal), una defensa de la necesidad del enjuiciamiento y la expulsión de normas y actos jurídicos aquejados de inconstitucionalidad, acompañada de la repulsa de cualquiera inclusión de estándares políticos y morales en los textos constitucionales que no harían más que otorgar discrecionalidad y oportunidad para el activismo al defensor de la constitución, más la puntualización de que este peculiar órgano ha de proceder siempre y solo de modo distinto de como proceden los órganos democráticos y representativos. El problema, claro, es que Kelsen defiende una idea no solo discutible sino que hoy por hoy algo rústica del sistema jurídico y del razonamiento judicial, así como de las relaciones entre derecho, moral y política. Cree, en efecto, que las normas completas o independientes de un sistema propiamente jurídico son solamente las prescriptivas, que estas se distinguen conceptualmente de las morales no tanto por su materia cuanto por su modo específicamente coactivo de regular la conducta, que cuando el juez no puede subsumir hechos bajo precisas normas jurídicas decide discrecional, o sea, políticamente, y que -aunque cabe hacer política con las normas jurídicas- la política siempre expresa juicios de valor, mientras el derecho consta de juicios deónticos regidos por el principio de imputación cuya validez (o sentido objetivo) es totalmente independiente de su mayor o menor coincidencia con expresiones valorativas.

Hay varias formas disponibles de sofisticar el análisis kelseniano. Partiendo por sus ideas de norma, sistema jurídico y moralidad. Hart, como se sabe, precisó las cosas con su distinción entre reglas primarias de deber y secundarias de poder -en cambio, su distinción entre conceptos esencialmente controvertidos y concepciones rivales sobre aquellos mismos no dice nada que Kelsen no haya dicho ya. Alchourrón y Bulygin, en otro capítulo muy conocido, acotaron dicho análisis con su perfilada idea de sistema jurídico y de la coacción como propiedad del mismo. Más recientemente, positivistas excluyentes, manteniendo la distinción entre el derecho que es y el que debiera ser, han admitido que en los sistemas jurídicos se utilizan (inevitablemente) estándares morales, como lo muestran los principios y derechos habitualmente protegidos tanto por el derecho interno como por el internacional ${ }^{36}$.

36 Por todos, ver S. Shapiro. Legalidad. Trad. D. PAPAYAnnis y L. RAmírez. Barcelona, M. Pons, 2014, pp. 319-344. 
En lo que respecta al control de constitucionalidad, que es lo que aquí me interesa, debe destacarse, a propósito de la polémica suscitada por la judicial review, que incluso algunos de sus propios partidarios creen que el defensor de la constitución no debe ser una institución que reproduzca simplemente el debate político democrático, sino un 'protector de la democracia', un 'foro de los principios ${ }^{37}$.

Para contener el expansivo papel de la judicatura constitucional que temía Kelsen (ese papel en cuya virtud el juez, en caso de conflicto entre la filosofía del texto constitucional y su peculiar filosofía política, llega a preferir esta su propia filosofía política ${ }^{38}$ ), pero sin renunciar como Kelsen a constituciones con normas valorativas (que un juez bien puede proteger y hacer operativas), Ely auspiciaba en materias de interpretación constitucional no un textualismo ni un liberalismo, sino algo diverso: entender que el control judicial de constitucionalidad puede tener justificación si y solo si el tribunal a cargo se constituye como un árbitro (referee) encargado de la supervisión (policing) del proceso de la representación (= the Process of Representation) ${ }^{39}$. En este sentido, el modelo de Ely sería el que siempre pareció encarnar en la Supreme Court de Estados Unidos el Justice Hugo Black -y no, en cambio, el que expresaron los magistrados que sustentaron el Roe $v$. Wade ${ }^{40}$. Esto acerca a Ely, por otra parte, al modelo de la Corte Warren, una Corte bastante activista, pero que precisamente habría llevado a cabo en varios de sus fallos (paradigmáticamente en la famosa nota al pie del fallo United States v. Carolene Products Co. de $1938)^{41}$ unas labores (a) de protección de la apertura igualitaria del proceso político mismo, incluidas las posibilidades de cambio y alternancia en el poder, así como (b) de extensión de la igualdad de trato hacia las minorías que pueden ser excluidas (o menoscabadas en sus posibilidades) de participar en tal proceso democrático ${ }^{42}$. Esto, para Ely, consiste en entender que la revisión judicial no habría de pretender la defensa de valores sustantivos, pues para eso no sirve una constitución ni menos los jueces que la protegen, sino solamente el resguardo de los procedimientos de la representación democrática, por ende políticamente igualitaria. Como ha dicho el Justice Linde: "como

37 He revisado sumariamente los juicios favorables y contrarios a la judicial review de Zagrebelsky, FerRajoli, Habermas, Alexy (quien remeda la idea de foro de los principios con la de una 'representación argumentativa'), RAwLS, DWORKIN, DAHL, WALDRON, NINO, FeRRERES Y BAYÓN: ver SOLARI. Constitucionalismo, cit., pp. 459-486.

38 Ver Ely. Democracy, cit., p. 2.

39 Ver Ely. Democracy, cit., p. 73.

40 Ver ELY. Democracy, cit., pp. 2-3.

41 Ver 304 U. S. 144, pp. 152-153 n. 4. Ver Ely. Democracy, cit., pp. 75-76.

42 Ver Ely, Democracy, pp. 73-75 y 103; para mayores detalles, ver pp. 105-179. 
mapa de gobierno, una constitución tiene que prescribir procesos legítimos, no resultados legítimos, si como la nuestra (y no como otros documentos más ideológicos de otros sitios) ha de servir a varias generaciones a través de tiempos cambiantes" ${ }^{43}$. Para esa labor de vigilancia del proceso democrático, creía Ely, los jueces constitucionales parecen estar especialmente bien situados, si y porque es correcto que ellos pueden realizar buenamente en materias de adjudicación constitucional una suerte de trabajo no tanto 'regulador (regulatory)' cuanto más bien 'antimonopolista (antitrust) ${ }^{44}$.

Coincidiendo solo parcialmente con Ely, Dworkin, en su seminal artículo de 1981: "El foro de los principios", se refería a la judicial review admitiendo que es "a un tiempo el orgullo y el enigma de la teoría del derecho estadounidense". En rigor, decía entonces, solo son concebibles cuatro alternativas para decidir los casos controvertidos de derechos constitucionales: o la de consultar la intención original de los redactores de la constitución, o la de encomendar a los jueces -como hace Ely- la custodia de las condiciones procedimentales de la democracia, o la de aceptar que los jueces los decidan apelando a sus propias convicciones sustantivas -limitando así al representante democrático e "imponiendo un veto a la política nacional"-, o la de suprimir el tutelaje judicial y "renunciar al poder instituido por Marshall" 45 . Las dos primeras fracasan y se autodestruyen, decía Dworkin, mientras la cuarta aniquila el consenso constitucional arraigado en Estados Unidos. Por todo lo cual solo quedaría disponible la tercera, la vía de la judicial review ${ }^{46}$. Y, si bien Dworkin llegó a conceder que esta no es estrictamente necesaria para la defensa de la constitución ${ }^{47}$, en 1981 la defendía, lo que es tanto como decir que aceptaba que "la Corte Suprema debe tomar decisiones políticas importantes", en el entendido de que las suyas han de ser decisiones tomadas por recurso a principios y no a políticas públicas, "esto es, decisiones sobre qué derechos tienen las personas en nuestro sistema constitucional, y no sobre cuál es la mejor manera de promover el bienestar general" 48 . Tal es su cometido, para cumplir con el cual debe proceder de acuerdo con el ideal sustancialmente democrático del tratamiento igualitario de los ciudadanos. El control judicial no es inevitablemente incorrecto (ni, tampoco, necesariamen-

43 Es cita de Due Process of Lawmaking. Nebraska Law Review 55/197, 1975, p. 255.

44 Ver ELY.Democracy, cit., pp. 101-103; una objeción a ello y una respuesta sucinta en la conclusión en pp. 181-183.

45 R. DworkIN. El foro de los principios. En: Una cuestión de principios. Trad. V. BosCHIROLI. Siglo XXI Editores, 2012, p. 53.

46 Ver Dworkin, Foro, pp. 53-55, en síntesis, y pp. 55-99, para su desarrollo.

47 Ver Dworkin, Justicia para erizos. Trad. H. Pons. México, FCE, 2014, pp. 480-484.

48 Ver Dworkin, Foro, p. 100. 
te correcto) por comprometer (o por salvar) la democracia, según Dworkin, sino que, aun con los errores (y aun horrores) cometidos por los jueces, esta institución "garantiza que las cuestiones más fundamentales de moral política sean por fin planteadas y debatidas como cuestiones de principio y no solo de poder político, transformación que no puede prosperar, o por lo menos no plenamente, dentro de los órganos legislativos", y esto no solo durante la adjudicación de cada caso en particular sino sobre todo antes y después de ella ${ }^{49}$. La judicial review no siempre es profunda ni convincente, pero es sin embargo valiosa. Pensando en Brown v. Board of Education, Dworkin pudo afirmar que la discusión moral y política sobre la segregación racial en la escuela (y más allá de la misma) "no hubiera tenido el carácter que tuvo sin la existencia y el simbolismo de las decisiones de la Corte" ${ }^{50}$. Por lo demás, aunque rechacemos encomendar nuestro gobierno a jueces-filósofos, Dworkin cree que jueces tuteladores de la constitución y sus derechos vienen a ser "una institución que traslada algunas cuestiones del campo de batalla del poder al foro de los principios", haciendo la promesa "de que los conflictos más profundos y fundamentales entre individuo y sociedad un día, en algún lugar, se convertirán en una cuestión de justicia" ${ }^{51}$.

\section{FUNDAMENTANDO UN CONSTITUCIONALISMO DÉBIL Y DIALÓGICO}

Ahora bien ¿podría justificarse otra alternativa, que se distinga de la defensa que hacen Kelsen, Ely y Dworkin -cada uno a su manera- de unos jueces constitucionales cuya palabra en lo que respecta al control de constitucionalidad sea institucionalmente la última? A mi modo de ver, sí. Se trata precisamente de algo que ni Kelsen ni Ely ni Dworkin han concebido: una judicatura que, permitiendo la argumentación sofisticada de principios, proceda al menos en ciertos contextos de manera limitada y colaborativa para con los órganos representativos precisamente por estar institucionalmente diseñada para evitar la hipertrofia y aun el activismo de los jueces. Para ello, por supuesto, se precisa una reflexión política y constitucional rigurosa, la que por el momento no diré tanto como que brilla por su ausencia, pero sí que sigue siendo escasa

49 Ver Dworkin, Foro, p. 101.

50 Ver Dworkin, Foro, p. 101.

51 Dworkin, Foro, p. 102. Más habría que decir de Dworkin, sobre todo fundando estas ideas sobre el control de constitucionalidad en su comprensión del razonamiento judicial, así como en su idea de la práctica hermenéutica que el derecho es, y en cuya virtud ha de rechazarse la tesis conceptual del positivismo acerca de la separabilidad entre moral y derecho. Sin embargo, esa indicación es suficiente, creo, para los fines de este texto. 
y poco crítica $^{52}$. En especial, es necesaria una reflexión que pondere de maneras matizadas y contextualizadas modelos realmente existentes que han sido organizados para hacer posible el despliegue de las virtudes tendencialmente racionalizadoras y deliberativas de una judicatura que ejerce control concreto de constitucionalidad según el ideal de constituirse en foro de los principios, de encarnar la representación argumentativa del pueblo. Mas, a la vez, se necesita que dicha reflexión considere y aun imagine modelos diversos del de revisión judicial fuerte, y por ende más o menos dialógicos, escépticos para con formas de tutela judicial democráticamente difíciles de aceptar, que abandonan la pretensión exorbitante de resolver y cerrar por adjudicación todo desacuerdo sobre derechos fundamentales.

Es el caso de la argumentación filosófico-política que, a la zaga de Rawls, ha ofrecido J.C. Bayón ${ }^{53}$. Para este, los diseños institucionales de toma política de decisiones son esquemas de 'justicia procesal imperfecta', por cuanto en

52 F. ATRIA, habiendo reflexionado profusamente acerca de los déficits de la judicial review, en cambio cuando clama por al menos derogar su enorme poder de control preventivo no entrega mayores detalles, si no me equivoco, acerca de qué caracteres podría tener una nueva arquitectura institucional de la misma. Esta falta de detalle institucional es algo usual en otros juristas de la (centro-)izquierda chilena, aunque en estos es más grave dada su escasa reflexión respecto de la idea misma de un control judicial de constitucionalidad. Por aquel y por estos, ver el artículo de J. I. NÚÑEZ, promisorio, si bien poco desarrollado (y que apela a la conveniencia de una jurisdicción constitucional difusa). "Pensando en la justicia constitucional de una nueva constitución: 'cada paloma es libre de ser el hipopótamo que quiera"', en H. TóRTORA y T. JORDÁN, coords. Estudios para una nueva constitución. Santiago de Chile, Metropolitana, 2014, pp. 698701; y los textos recogidos en F. Zúñiga, coord. Nueva Constitución y momento constitucional. Visiones, antecedentes y debates. Santiago de Chile, Legal Publishing/Thomson Reuters, 2014, esp. pp. 15-139, sobre todo pp. 29, 70-71, 74, 106, 118-122. Este último libro también contiene los programas de gobierno de casi todas las candidaturas de (centro-)izquierda a las elecciones presidenciales del año 2013, cuyas alusiones institucionales, si bien permiten purgar al actual TC de algunos de sus defectos presentes, parecen igualmente elementales y poco imaginativas (ver pp. 197-198, 224, 232, 238, 312-313 y 326-327). No es la primera vez que en Chile se reflexiona de maneras insularizadas o deficientes acerca del diseño de instituciones relevantes. Sobre la historia y los problemas del control de constitucionalidad en Chile (incluyendo al recurso de inaplicabilidad por inconstitucionalidad, del que en este texto conviene repetir que no me ocupo), ver, entre otros: E. FreI et al. Reforma Constitucional de 1970. Santiago de Chile, Editorial Jurídica, 1970; F. ATRIA. Inaplicabilidad y coherencia: contra la ideología del legalismo. Revista de Derecho. Universidad Austral de Chile, 12/1, 2001, pp. 119-156; JAVIER COUso y AlBerTO CoDDOu. La naturaleza jurídica de la acción de inaplicabilidad en la jurisprudencia del Tribunal Constitucional: un desafío pendiente. En: Estudios Constitucionales. Universidad de Talca, 8/2, 2010, pp. 389-430; ENRIQUE NAVARRo. El control de constitucionalidad de las leyes en Chile (1811-2011). Cuadernos del Tribunal Constitucional,43, 2011; DANTE FIGUEROA. Constitutional Review in Chile Revisited: A Revolution in the Making. Duquesne Law Review, 51, 2013, pp. 387-419.

53 J. C. BAYÓn. Democracia y derechos: problemas de fundamentación del constitucionalismo. En: M. CARBonell y L. GARCía, coord. El canon neoconstitucional. Madrid, Trotta, 2010, pp. 285-355. Aquí resumo este alegato en favor de un constitucionalismo débil tal como lo 
ellos hay criterios independientes del procedimiento que permiten evaluar la justicia de sus resultados, pero no hay seguridad sino mera probabilidad de que el procedimiento produzca tales resultados. Y entre los modelos realmente existentes para tomar decisiones, el del estado (con control) constitucional sería el esquema institucional menos imperfecto de todos, precisamente en tanto que "no asegura, sino que meramente hace probable, en mayor o menor medida, la corrección del resultado". Pues bien notablemente Bayón agrega aquí que un diseño político puede y tiene que juzgarse no solo por este su valor instrumental, es decir, el de los resultados que probablemente produce, sino también por su valor intrínseco, vale decir, el mérito que posee en tanto en cuanto institucionalización de la igualdad política. Y que el balance entre uno y otro valor es estrictamente contextual. Esto supone que la justificación de la judicial review debería despedirse de juicios universales para abrazar en vez unos bien particulares: si en las circunstancias de una comunidad política su probable valor instrumental (qué se decide, aquí sí y cuán bien se protegen los derechos) compensa sus intrínsecas desventajas democráticas (cómo se decide, aquí contramayoritariamente). Esta 'tesis de la dependencia contextual', pues, hace posible tanto que se justifique como que no alcance justificación el control judicial de constitucionalidad in abstracto. Desde este punto de vista la justicia constitucional requeriría una precisa justificación, para lo cual Bayón propone el siguiente criterio: "aunque el conflicto entre el valor intrínseco y el valor instrumental de un procedimiento es siempre posible, las circunstancias sociales en las que el procedimiento mayoritario realiza en mayor medida su valor intrínseco tienden a coincidir con aquellas en las que menos reticencias hay que tener en relación con su valor instrumental, con aquellas, en suma, en que son más escasas las razones para presuponer que, en comparación con él, desplegará sistemáticamente un mayor valor instrumental un procedimiento que incorpore restricciones contramayoritarias" ${ }^{54}$.

Este sutil argumento de Bayón, según creo, no ha de ser tomado como una racionalización de instituciones existentes, democráticamente injustificables, pero también difícilmente erradicables en ciertos contextos políticos y jurídicos, sino más bien como una auténtica razón, cuando su mérito instrumental supera a su deficiencia intrínseca, favorable a la justicia constitucional, si bien compatible con alguna forma de constitucionalismo débil. Empero, el argumento de Bayón implica el valor instrumental de la judicial review sin desarrollar el punto: ¿por qué, y aun cuando solo fuera en ciertos contextos, puede justificarse instrumentalmente, o sea, por la corrección sustantiva de

he presentado en otro lugar, pero sin someterlo entonces a juicio ni discernir sus consecuencias institucionales: ver SOLARI. Constitucionalismo, cit., pp. 484-486.

54 BAYÓn. Fundamentación, cit., p. 354 (antes, pp. 314-316, 327-331, 340 y 344). 
los resultados que probablemente produce, un control judicial de constitucionalidad abstracta -y no, por ej., alguna variante de control parlamentario? ¿Qué tiene de peculiar la jurisdicción que permita salvar no solo la posibilidad sino sobre todo la deseabilidad de una judicial review pese a su intrínseco demérito democrático? Estas son preguntas exigentes, pero abordables considerando las distintas circunstancias ${ }^{55}$ que rodean o encuadran a los debates constitucionales, respecto de cuya materia -el conflicto político- habría que preguntar si permite su sometimiento, al menos provisional, a una forma jurídica de resolución de controversias. Para responder positivamente, según creo, hay que ir por pasos contados.

Por una parte, las cuestiones constitucionales y de derechos fundamentales se insertan, como es obvio, dentro de lo que, en el vocabulario de Waldron, se llaman 'circunstancias de la política', que son las de un grupo humano que ha de colaborar a través del tiempo pese a sus diferentes concepciones acerca de lo que es justo, precisamente para sobrellevarlas en común cuando llega el momento de tomar decisiones vinculantes ${ }^{56}$. Es algo en lo que Rawls insistía cuando hablaba del 'consenso entrecruzado (overlapping consensus)' a que pueden arribar distintas concepciones comprehensivas del bien, y que es, decía, otra manera de plantear el clásico problema de la tolerancia ${ }^{57}$. En este sentido, el problema de identificar los límites de la tolerancia puede ser encomendado al proceso político con un añadido institucional dotado de algún valor epistémico. En todo caso, el sentido justificatorio de institucionalizar judicialmente el control constitucional apela a que su deficiente valor intrínseco (por ser contramayoritario) sea compensado con su mayor valor instrumental y eo ipso con ese valor al que cabría denominar como epistémico, discursivo, racionalizador o argumentativo. ¿En qué consiste esto?

Cuando se enfrentan los conflictos constitucionales hay que conceder que existen otras circunstancias o, quizá mejor, que existen unas circunstancias no solamente políticas sino también jurídicas, las que posibilitarían arreglos institucionales que, sin sustituir al proceso democrático, operen a su respecto como contrapunto, como un complemento racionalizador del mismo. Esto no impide entender que la mejor justificación de una democracia deliberativa es más procedimental (o intrínseca) que instrumental y epistémica, pues reposa en

55 Hablar de las circunstancias remite, claro, a HUME cuando detallaba las circunstancias de la justicia en el Treatise o en la Moral Enquiry, un lenguaje que después popularizara y prolongara RAWLS en su Theory.

56 Ver Jeremy Waldron. Derecho y desacuerdos. Trad. J. L. Martí y Á. Quiroga. Madrid/Barcelona, M. Pons, 2005, pp. 123-124.

57 Ver John Rawls. El liberalismo político. Trad. A. DomÈneCh. Barcelona, Crítica, 2013, pp. 19-24. 
la igualdad política que es el fundamento de las instituciones representativas que toman decisiones mediante una profusa deliberación colectiva, y no en la calidad sustantiva (teóricamente identificable y aun defendible) de dichas decisiones que son sus resultados. Si esto es prometedor, sería entonces posible y deseable 'filosoficar' la justificación democrática con un dispositivo institucional que hiciese probable un incremento de la racionalidad argumentativa que el proceso democrático-deliberativo per se no asegura ${ }^{58}$. Las controversias políticas que atraviesan a una comunidad política no serían, de este modo, eliminadas ni por la constitución ni por los jueces constitucionales, sino procesadas y resueltas a través de una forma judicial o, más propiamente, cuasi o semijudicial, justo por estar entregadas a letrados que, sin ser imparciales sino estando involucrados en el mismo, son pese a todo capaces de sofisticar filosóficamente las razones para su resolución, una resolución que será finalmente deliberada y decidida por los órganos democráticos ${ }^{59}$.

¿Es un mecanismo propiamente judicial o más bien semijudicial el de la judicial review? El asunto, planteado ya por Kelsen, merecería una discusión detallada. Por ahora, diría lo que sigue. Kelsen puede tener razón y la actividad de control de constitucionalidad ser descrita como una actividad judicial, si bien idiosincráticamente. Kelsen, recordemos, defendía para ella la 'forma judicial', vale decir, la de una discusión pública de intereses que contienden. Pensaba que el razonamiento del juez constitucional estaba compuesto por una premisa normativa (la constitucional), una fáctica (la que consistiría en el la producción de una ley u otra norma) y una conclusión (la decisión respecto de la constitucionalidad o inconstitucionalidad de la producción del acto legislativo o administrativo -precisamente por estar este procedimental o materialmente mandado o cuando menos permitido por la constitución, en

58 Entender que los jueces, sobre todo resolviendo cuestiones constitucionales, han de realizar un razonamiento sumamente filosófico, no es en modo alguno una novedad. Véase por ejemplo el argumento de DwORKIN: "en las áreas más públicas del derecho [...], la necesidad que tienen los jueces de confrontar asuntos filosóficos es más grande y evidente [que cuando conocen de materias de derecho privado]. Los jueces constitucionales toman elecciones filosóficas no de manera ocasional cuando se presenta algún caso particularmente difícil, sino como una cuestión de rutina", como al tener que resolver conflictos respecto de los alcances de la libertad de expresión, o de la democracia, o de la igualdad, o del significado de 'persona', etc.: R. Dworkin. ¿Deben nuestros jueces ser filósofos? ¿Pueden ser filósofos?. Trad. L. García. Isonomía, 32, 2010, p. 13.

59 "No estoy suponiendo que algún incremento de la sofisticación judicial respecto a la filosofía eliminaría la controversia entre los jueces [...] La reflexión filosófica pone a prueba los supuestos endebles y, por lo tanto, es más probable que produzca un mayor número de cambios que cualquier otro tipo de reflexiones. No estoy promoviendo una mayor sofisticación filosófica porque eliminará o reducirá la controversia, sino porque la hará más respetable o, al menos, más iluminada": Dworkin, Jueces, p. 27. 
el primer caso, o prohibido, en el segundo). Claro es que esta es solo una descripción posible de lo que hace el defensor constitucional, pues también cabe describir dicha actividad legislativa o cuasilegislativamente -como reconocía el mismo Kelsen. Y si la acción de un órgano público como el que practica el control abstracto de constitucionalidad es peculiar, con mayor razón tendrá que ser descrita múltiplemente ${ }^{60}$. Así se cohonestaría el argumento kelsenita acerca del carácter cuando menos parcialmente judicial del defensor de la constitución incluso en un modelo débil, donde el juez constitucional tiene el cometido de aplicar argumentativamente la constitución o, quizá mejor, de velar discursivamente por ella, cosa ciertamente desafiable por parte del representante democrático, lo que significa que lo que debe hacer dicho órgano democrático y cómo debe hacerlo es algo que debe decidir este mismo, pero reconociendo ciertos parámetros constitucionales (orgánicos y iusfundamentales) a los que debe ceñirse.

No cabe duda de que habría más que decir. Tienen que buscarse procedimientos parlamentarios y administrativos que mejoren lo que podría denominarse la legitimación material a posteriori de las decisiones democráticamente tomadas, haciendo probable que a través de ellas se satisfaga no el interés de una sola facción sino el de todos ${ }^{61}$. Ahora bien, esta legitimación material alcanza también a la jurisdicción, si bien de un modo típico: "cuando de lo que se trata es de legitimar decisiones que pueden ser anticipadas en abstracto y

60 De hecho, entre los procesalistas contemporáneos este asunto es discutido, lo que no obsta a que a veces esta tesis halle respaldo, en la medida en que el proceso constitucional -conformado ya sea fuerte, ya sea débilmente- sea descrito como "un verdadero proceso" que intenta proteger la supremacía y los principios constitucionales, como los que garantizan derechos, ante actos y normas de la autoridad pública (y aun cuando, agrego, no sea más que a través de la imposición de estrictas cargas argumentativas al representante democrático). Ver por ejemplo el juicio matizado de MARINONI, PÉREZ y NúÑEZ, Fundamentos: "el tratadista alemán GEIGER considera que el proceso constitucional es pura ficción [...] Explica que en el proceso civil, el Estado decidiría con carácter general sobre pretensiones que le son ajenas y en presencia de partes que son portadoras de derechos propios. En el proceso constitucional es diferente y su existencia es posible como consecuencia de una ficción jurídica, porque son manifestaciones, en definitiva, de una y la misma persona jurídica del Estado. [Con todo,] consideramos que el proceso constitucional (como una de las vías de realización de un fenómeno más general, cual es la justicia constitucional) resulta un verdadero proceso, que tiene por fin la protección de los principios constitucionales, especialmente los que otorgan derechos a los individuos, frente a las decisiones legítimas de la autoridad pública, y la tutela de la supremacía constitucional [...] Pero la tesis de GEIGER podría ser correcta en supuestos de justicia constitucional, donde técnicamente no hay un 'proceso', sino apenas un 'procedimiento constitucional'": pp. 46-47.

$61 \mathrm{Al}$ respecto, ver F. ATRIA. Legislación, jurisdicción, administración. En: P. GREZ et al., coords. Una vida en la Universidad de Chile. Celebrando al Profesor Antonio Bascuñán Valdés. Santiago de Chile, Legal Publishing, 2014, pp. 141-147. Seguramente nadie ha hecho en estos tiempos más que WALDRON por precisar la arquitectura de la deliberación y la toma de decisiones en los parlamentos: ver Desacuerdos, pp. 29-174. 
que en general no necesitan ser sensibles a consideraciones de oportunidad o conveniencia, la legitimación material asume la forma de la vinculación inmediata y concreta a la ley" ${ }^{\text {"2 }}$. La justificación instrumental-epistémica aquí sugerida para la jurisdicción constitucional implica, pues, que en un sentido relevante es posible entender que la sujeción del juez constitucional a la constitución es analogable a la sujeción del juez ordinario a la ley. También y por lo mismo, que hay analogía entre la independencia del juez ordinario y la del juez constitucional. Y, también por la misma razón, que tan posible es que el juez ordinario decida algo con lo que él en persona no esté sustantivamente de acuerdo, como posible es que el resultado del control de constitucionalidad no tenga un happy end para la propia filosofía política del juez constitucional. Lo que reafirmaría que la distinción entre conceptos constitucionales y plurales concepciones filosóficas de los mismos, si bien no permite que las controversias políticas sean eliminadas (sino más bien, como ya decía, esclarecidas, ilustradas), tampoco sugiere que las peculiares convicciones del juzgador sean siempre las que doten de contenido final a sus decisiones constitucionales (sino, en cambio, que la convicción interpretativa del juzgador acerca de lo que el texto constitucional exige o prohíbe perfectamente puede discrepar de lo que él personalmente exigiría o prohibiría).

Un mecanismo como este, en suma, funcionalizaría cierta auctoritas en un entorno democrático, en el entendido de que otorgaría sitio institucional al punto de vista de la filosofía política dentro de un procedimiento de toma de decisiones colectivas diseñado no aristocráticamente sino a partir del ideal de la igualdad política ${ }^{63}$. Y lo hace precisamente en el sentido de fungir de dispositivo que sutiliza la deliberación democrática de decisiones, auxiliando así -tal es su pretensión- en la revelación de las deficiencias racionales (referibles sobre todo a los diversos derechos fundamentales, incluyendo por supuesto a los envueltos en las instituciones democráticas) de la actividad gubernamental y parlamentaria. Así, se contaría con una justificación adicional

62 ATRIA. Legislación, cit., p. 153 (ver también pp. 148-153 y 173-181).

63 "El procedimiento de decisión democrática no garantiza la justicia sustantiva de los resultados decididos [...] Puede haber sistemas de decisión (incluso no deliberativos [...]) que producen mayor legitimidad [...] Reconocer las [...] restricciones sustantivas al procedimiento democrático, sin embargo, presupone la legitimidad del propio procedimiento, que en realidad se justifica en último término como manifestación del derecho a una igual autonomía de todos los ciudadanos para decidir sobre los asuntos colectivos [...] [Los filósofos políticos] se reservan el juicio ante las deliberaciones de unos u otros sistemas políticos, hasta llegar a impugnarlos como ilegítimos si no garantizan resultados suficientemente satisfactorios en términos de derechos básicos. Esa reserva del juicio, por lo demás, es también el 'privilegio' que el filósofo político debe conceder a cualquiera que, en cuanto individuo, quiera hacer uso de su razón frente a las deliberaciones colectivas": ALFONSO RUIZ Miguel. Lo no deliberable de la democracia deliberativa. Diritto \& questioni pubbliche, 9, 2009, pp. 353-355. 
para que, al momento de diseñar nuestras instituciones, las circunstancias de la política sean completadas por otras circunstancias, las cuales, si no de otro tipo, sí son de uno que posibilita la mejora del rendimiento instrumental y epistémico de la deliberación democrática. Son, en la terminología de Shapiro, las denominadas 'circunstancias de la legalidad', circunstancias típicas de una comunidad que tiene serios problemas morales cuyas soluciones "complejas, controvertidas o arbitrarias" requieren no de abordajes improvisados, espontáneos, privadamente acordados, socialmente consensuados o que respondan a meras jerarquías personales, sino de "tecnologías sofisticadas de planificación social que solo ofrecen las instituciones jurídicas" 64 . Y precisamente entre estas formas jurídicas de planificar y reducir problemas de alta complejidad, entre estos procedimientos que mejorarían epistémicamente, sin tutelar políticamente, la deliberación democrática que lleva a la toma de decisiones, se hallan, como es obvio, los de un control (cuasi)judicial de constitucionalidad filosóficamente sofisticado e institucionalmente débil y dialógico ${ }^{65}$.

64 SHAPIRO. Legalidad, cit., p. 217 (ver pp. 216-220). VilaJOSANA, análogamente, ha hablado de las 'circunstancias de la jurisdicción', pues "la actividad consistente en la interpretación y la aplicación del derecho llevada a cabo por los órganos jurisdiccionales, en general, y por un tribunal constitucional, en particular, está sometida a una serie de imponderables, nacidos del carácter de esa misma actividad", todos los cuales limitan tanto lo posible como lo deseable: particularmente la vaguedad y la textura abierta del lenguaje natural que utilizan los textos normativos, las lagunas y antinomias debidas a que las normas jurídicas forman sistemas normativos, así como la presencia en el derecho de conceptos esencialmente controvertidos y de principios fuertemente morales que pueden colisionar entre sí: ver J. M. VILAJOSANA. Precondiciones para el análisis del conflicto entre Tribunal Constitucional y Parlamento. Isonomía, 36, 2012, pp.97-104. Sobre el carácter político de toda interpretación jurídica, pero especialmente de la constitucional, ver JERZY WRÓBLEWSKI. Constitución y teoría general de la interpretación jurídica. Trad. A. AzURZA. Madrid, Civitas, 1988, pp. 111-114.

65 Esto, que completa el argumento de BAYÓN, puede asentarse en otra línea argumentativa esbozada por él, cuando -aunque sin desarrollar este mismo punto-dice: "si el valor epistémico desempeña realmente algún papel, habría de ser más bien en la justificación de alguna forma de procedimiento democrático en particular frente a todas las demás", lo que sería tanto como decir -algo que el propio BAYÓN no hace- que la intrínseca justificación de una democracia podría permitir un injerto institucional democráticamente disvalioso como la judicial review en tanto en cuanto este sea justificado instrumentalmente en ciertos contextos políticos y jurídicos por su valor epistémico: J. C. BAYÓN. ¿Necesita la república deliberativa una justificación epistémica? Diritto \& questioni pubbliche, 9, 2009, p. 224. DwORKIN llegó a hacer afirmaciones semejantes: "el control de constitucionalidad mejora la legitimidad general al aumentar las probabilidades de que la comunidad adopte y haga cumplir alguna concepción apropiada de la libertad negativa y de una distribución equitativa de recursos y oportunidades, así como de la libertad positiva": Dworkin, Erizos, p. 483. Incluso más: esta forma de argumentar requeriría una reflexión pormenorizada, que aquí no podré brindar, que explore si y cómo podría institucionalizarse lo que Kant descubriera en la tercera Crítica: la facultad de juzgar, juicio o discernimiento (Urteilskraft). Esta, que puede ser determinante (bestimmende) o bien reflexionante (reflektierende), ha sido usualmente considerada solo a propósito del gusto estético y de la teleología natural, pasándose 


\section{MODELANDO EL DIÁLOGO ENTRE CORTES Y PARLAMENTOS}

Mas, aunque toda esta discusión polifónica se diría que corrige y mejora argumentaciones como las de Kelsen, Ely y Dworkin, deja abierta la pregunta por la especificación institucional de alternativas a la hipertrofia que a veces acompañan a la judicial review (tanto à la norteamericana como à la europea, y por cierto à la chilena), pero sin que por ello promuevan su completa eliminación. Para no encarar esta cuestión muy genéricamente, conviene apuntar desde ya que hay variados modelos existentes de constitucionalismo, y que algunos de ellos, más bien recientes, parecen caracterizarse por un cierto carácter débil y dialógico, lo que significa que institucionalizan una revisión constitucional que -allende el modelo norteamericano de checks and balances con revisión judicial fuerte y el de Westminster con supremacía parlamentaria total y sin revisión judicial ninguna- promueven en cambio una suerte de cooperación constitucional basada en la deliberación o diálogo democrático entre jueces

por alto su relieve político y jurídico. El juicio es la capacidad de enjuiciar o evaluar particulares imparcialmente ('esto es malo', 'esto es bello', etc.), y en hacerlo sea a partir de reglas o leyes generales dadas de antemano (cuando es determinante), sea aun sin contar con ellas (cuando es reflexivo). H. ARENDT, como se sabe, es responsable de una aguda (aunque, todo hay que decirlo, libérrima) lectura de la tercera Crítica kantiana por medio de la cual ha tratado de exponer lo que hubiera sido la filosofía política de KANT (ver ARENDT, 2003: passim, y su interpretación de los $\S 39, \S 40$ y $\$ 41$ de dicha Crítica: pp. 126-142; ver KANT 1992: 202-208/Ak. V 291-298 [B153B165]). Tal filosofía, sugiere ARENDT, es distinta, si bien no está separada, de su filosofía moral, y pende de una (muy argumentada) analogía entre el juicio estético y el político, en los cuales la distinción que hace KANT entre la perspectiva del actor y la del espectador permitiría afirmar que "los casos paradigmáticos del ejercicio de la facultad del juicio son casos excepcionales de independencia respecto a opiniones prefabricadas o de resistencia contra la indiferencia de la mayoría" (WELLMER, 2000: 261). Para mí, es de interés que el juicio pueda ser considerado no solo reflexivamente como político sino también determinantemente como jurídico, en el preciso sentido de que el espectador que evalúa acontecimientos particulares realice, en cuanto tal e institucionalizadamente, actos judicativos. Políticamente hablando, esto supone que el espectador de la historia puede enjuiciar los eventos alejándose del punto de vista del actor comprometido e interesado en ellos, cosa que en KANT aflora con espectacular nitidez a propósito de sucesos revolucionarios de su época, como la revolución americana, la francesa, etc. Jurídicamente hablando, esto se aprecia de modo decisivo en los actos de interpretación y aplicación del derecho, lo que equivale a decir que el punto de vista del espectador imparcial que emite el juicio jurídico sea precisamente el del... juez. Esto es algo que la propia ARENDT pusiera en evidencia ya desde su radical y polémica interpretación del proceso a que fue sometido EICHMANN en Jerusalén (ver 2008), que es una prolongación, aunque también una crítica y una mejora, de sus reflexiones previas sobre los totalitarismos (proceso en el cual pasa, como es sabido, de detectar la radicalidad del mal a diagnosticar la banalidad del mismo). Es algo, claro, que ya han explorado varios lectores de Arendt; ver, entre otras, las recientes perspectivas explícitamente filosófico-jurídicas de BILSKY (1996) y de ROSENMÜLLER (2013, basada en una previa disertación doctoral acerca del puesto del derecho en el pensamiento de ARENDT, con especial atención a las peculiaridades del juicio en la actividad juzgadora (= Urteilen) del Tribunal Constitucional Federal alemán). 
y legisladores, reservando incluso la última palabra no al juzgador sino al legislador. Es lo que se ha dado en llamar el 'nuevo modelo constitucional de la Commonwealth' ${ }^{66}$. El cual mantiene cierto control de constitucionalidad

66 Estos nuevos modelos de la Commonwealth estarían desplazando al antiguo modelo de Westminster, el cual quizá solo persiste en Australia, donde casi no hay constitucionalización de derechos pero sí rigidez constitucional: ver S. LINARES. El diálogo democrático entre las cortes y las instituciones representativas. Revista mexicana de sociología 70/3, 2008, p. 501; E. RUIZ. La excepción constitucional australiana. El debate sobre la protección jurídica de los derechos y el modelo del diálogo institucional. Revista española de derecho constitucional, 95, 2012, pp. 95-138; y StePhen Gardbaum. The New Commonwealth Model of Constitutionalism. Theorie and Practice. Cambridge, CUP, 2013, esp. pp. 204-221. Sobre esta nueva forma de constitucionalismo débil, ver MARK TUSHNET. Weak Courts, Strong Rights: Judicial Review and Social Welfare Rights in Comparative Constitutional Law. Princeton, Princeton University Press, 2009, esp. pp. 3-76; Rosalind Dixon. Weak-form judicial review and american exceptionalism. Chicago Public Law and Legal Theory. Working Paper 348, 2011; Joel Colón-Ríos. Weak Constitutionalism: Democratic legitimacy and the question of constituent power. New York, Routledge, 2012, esp. pp. 1-16 y 152-174 (de las cuales se halla una suerte de anticipo, sobre todo por el ideal de "un constitucionalismo débil al servicio de una democracia robusta", en el artículo escrito con Allan Hutchinson. Constituciones duraderas. Una crítica democrática. Trad. J. PABón y K. Stone. Anuario de Derecho Público. Universidad Diego Portales, 2, 2011, pp. 447-451); S. Gardbaum. New Commonwealth, pp. 19-94; y Joel Colón-Ríos. A new typology of judicial review of legislation, Global Constitutionalism, 3/2,2014, pp. 143-169, quien aquí distingue la revisión judicial débil (weak judicial review) característica de Canadá, Nueva Zelanda y Reino Unido de la que llama revisión de estructura básica débil (weak basic structure review) propia de Colombia, Bolivia y Ecuador (pp. 145-148 y 157-162, respectivamente), una distinción cuyo examen aquí no se abordará. Por otra parte, conviene prevenir que tampoco se abordarán aquí aquellos diseños institucionales que, sobre todo en relación con los derechos sociales, dotan a las judicaturas constitucionales de verdaderos poderes de 'agenda política' a través del llamado 'litigio de reforma estructural' ( $;$ todo una forma de activismo y aun de vandalismo judicial!), cuyo punto de partida parece ser el Brown v. Board of Education de 1954 en Estados Unidos y algunas de sus manifestaciones recientes más conspicuas, los casos Grootboom (Government of the Republic of South Africa c. Grootboom) de 2000 y TAC (Minister of Health c. Treatment Action Campaign) de 2002 ventilados ante la Corte Constitucional de Sudáfrica. En igual sentido estructural, se han llegado a acuñar nociones como las de 'inconstitucionalidad por omisión legislativa' (como en la Constitución de la ex Yugoslavia de 1974, en la Constitución portuguesa de 1976 y en la brasileña de 1988) y la de 'estado de cosas inconstitucional' (como ha hecho la Corte Constitucional de Colombia desde 1997). ver S. LinARES, Diálogo, pp. 510-512 y 525-531. Esto, a veces, incluye un activo recurso a audiencias públicas y a los amicus curiae: ver RICARDO LOREnZETTI. Las audiencias públicas y la Corte Suprema. En: R. GARGARELla, comp. Por una justicia dialógica. El Poder Judicial como promotor de la deliberación democrática. Buenos Aires, Siglo XXI Editores, 2014, pp. 345-354. El especial impacto que todo esto ha tenido en el marco de la protección judicial de los derechos sociales ha merecido una cada vez más detenida atención: ver, entre muchos otros, MALCOLM LANGFORD, ed. Teoría y jurisprudencia de los derechos sociales. Tendencias emergentes en el derecho internacional y comparado. Trad. C. Morales. Bogotá, Universidad de los Andes, 2013; Rosalind Dixon Para fomentar el diálogo sobre los derechos socioeconómicos. Una nueva mirada acerca de las diferencias entre revisiones judiciales fuertes y débiles. En: R. Gargarella, comp. Por una justicia dialógica. El Poder Judicial como promotor de la deliberación democrática. Trad. H. SALAS. Buenos Aires, Siglo XXI Editores, 2014, pp. 51-103; CÉSAR RODRíGUEZ. El activismo dialógico y el impacto de los 
protector de los derechos constitucionales, pero reservando la última palabra institucionalmente hablando al parlamento.

Más específicamente, se ha caracterizado a este modelo por la cooperación, la distorsión y la deferencia ${ }^{67}$. La cooperación entre todos los poderes estatales tiene como finalidad resguardar los derechos constitucionales, cosa que en estos arreglos institucionales en general se lleva a cabo tanto a través de una cláusula que permite la limitación de tales derechos siempre que sea razonable y democráticamente justificada, como también a través de una práctica estandarizada de previa revisión parlamentaria de la constitucionalidad de los proyectos de ley (incluso con la obligación ministerial de informar por escrito al parlamento las eventuales afectaciones de derechos ínsitas en los proyectos). La distorsión en favor de los jueces de la soberanía democrática (expresada en la legislatura y el gobierno) se manifiesta o bien como poder judicial de invalidación de leyes y actos administrativos declarados inconstitucionales por afectar derechos, o bien como poder judicial de interpretación que trata de salvar tal inconstitucionalidad por vías alternativas (aditivas o sustractivas), o bien como potestad jurisdiccional no invalidatoria sino declaratoria de incompatibilidad con los derechos constitucionales. La deferencia, en fin, hacia los poderes con legitimidad democrática directa es lo que permite afirmar que la última palabra es la del legislador, en la medida en que será este el que decidirá si asume la invalidación, la incompatibilidad o la interpretación alternativa del juez.

\section{El modelo canadiense}

Entre los ejemplares de este nuevo modelo constitucional se hallan el canadiense, el inglés y el neozelandés ${ }^{68}$. Quizá el más intensamente estudiado y discutido sea el de Canadá, donde (entre 1960, con una ley ordinaria aún vigente: la Canadian Bill of Rights, y 1982, con una carta formalmente constitucional: la Canadian Charter of Rights and Freedoms) parece haberse creado

fallos sobre derechos sociales, ibíd., pp. 211-244. Todo esto, repito, merecería un tratamiento que será preciso realizar en otra oportunidad.

67 Sigo aquí a MARIANO MELERO. La interpretación constructiva en el constitucionalismo commonwealth: ¿activismo o vandalismo judicial? Eunomía, 5, 2013/2014, esp. pp. 29-34.

68 No abordaré aquí el modelo israelí; al respecto, ver S. LiNARES, Diálogo, pp. 505-509 y 517-518; ADAM DODEK. A Tale of Two Maps: The Limits of Universalism in Comparative Judicial Review. Osgoode Hall Law Journal, 47/2, 2009, pp. 311-314; RIVKA WEILL. Hybrid Constitutionalism: The Israeli Case for Judicial Review and why we Should Care. Berkeley Journal of International Law vol. 30, n. ${ }^{\circ}$ 2, 212, pp. 349-411; RivKA WeILL. The New Commonwealth Model of Constitutionalism Notwithstanding: On Judicial Review and Constitution-Making. The American Journal of Comparative Law, 62, 2014, esp. pp. 130, 153-154, 164 y 168-169. 
esta forma de revisión judicial débil ${ }^{69}$ que luego se ha expandido por el área del tradicional modelo de Westminster ${ }^{70}$. Algunos de sus rasgos son los que siguen. La Carta de 1960 obliga al ministro de justicia a informar por escrito al Parlamento de los proyectos de ley que puedan ser incompatibles con los derechos allí protegidos, aunque la Carta de 1982 ha llevado, en la práctica constitucional, a una cuasi presunción de la compatibilidad de tales proyectos con los derechos, con lo cual ese deber de informar casi ha desaparecido. En todo caso, tanto el gobierno como la legislatura suelen analizar las posibles afectaciones de derechos que involucran los proyectos legislativos y si ellas pueden justificarse razonablemente desde el punto de vista democrático. En dicho análisis de la constitucionalidad de las leyes, los otros órganos estatales siguen el mismo esquema que utilizan los jueces, cosa que les permite a aquellos anticipar (y disponer de antemano de una batería de razones contra) posibles objeciones judiciales a sus proyectos. Los jueces, según la sección 52 de la Carta de 1982 (tal como ha sido entendida por la Corte Suprema), pueden bien inaplicar leyes incompatibles con los derechos, bien suspender la invalidación de ellas por cierto período para que en ese intertanto el gobierno corrija la incompatibilidad, bien interpretarlas para evitar la incompatibilidad. Pero, cuando miden la compatibilidad de leyes y derechos aplicando un test acerca de la proporcionalidad entre los fines legislativamente pretendidos y los medios que la ley arbitra para alcanzarlos, en general muestran tomarse más en serio la deliberación parlamentaria y gubernamental acerca de la constitucionalidad de las leyes que lo que suele hacer la Corte Suprema estadounidense.

En su citado artículo de 1997, Hogg y Bushell dicen que la Carta de Derechos y Libertades de 1982 no es tan mala después de todo. Esta Carta, justamente a través de la revisión judicial, "es parte de un 'diálogo' entre los jueces y

69 Esto ha sido contestado. Ver por ejemplo el texto ya mencionado de Colón-Ríos. Judicial review, cit., pp. 145-147, donde se señala que antes que en la sección 2 de la Canadian Bill of Rights hay antecedentes latinoamericanos bastante claros de revisión judicial débil, como en la Constitución venezolana de 1830 (arts. 186, 187 y 224), la colombiana de 1858 (art. 50) y la ecuatoriana de 1945 (art. 160.4).

70 Para presentar este modelo sigo a LiNARES, Diálogo, cit., pp. 494-497 y 515-516, a M. Melero, Vandalismo, pp. 30, 32 y 34, pero sobre todo a Peter Hogg y Allison Bushell. El diálogo de la Carta entre los tribunales y las Legislaturas (o quizá la Carta de Derechos no sea algo tan malo después de todo). Trad. S. SERESEvsky. En: R. Gargarella, comp. Por una justicia dialógica. El Poder Judicial como promotor de la deliberación democrática. Buenos Aires, Siglo XXI Editores, 2014, pp. 17-49, además de otros textos que mencionaré más adelante. Para una contextualización de la novedad y peculiaridades del modelo canadiense respecto del modelo estadounidense, ver R. GARGARELLA, "El nuevo constitucionalismo dialógico frente al sistema de los frenos y contrapesos", ibíd., pp. 119-158. Para mayores detalles sobre el modelo canadiense, ver GARDBAUM, New Commonwealth, cit., pp. 97-128. 
las legislaturas" ${ }^{11}$. Este diálogo es posible "cuando una decisión judicial está abierta a la revocación, modificación o anulación legislativa"72. Si un tribunal objeta la constitucionalidad de una ley, el legislador puede responder purgando dicha inconstitucionalidad para, así, tratar de obtener aquellos objetivos que judicialmente han sido impedidos. Entonces, cuando se produce una 'secuela legislativa', los jueces provocan un debate público acerca de los derechos y libertades protegidos constitucionalmente que, sin decisión judicial, no hubiera tenido lugar. Si la decisión final es tomada democráticamente, esto es, por el legislador y no por un tribunal, puede decirse que el diálogo acaba con una decisión democrática ${ }^{73}$. Estudiando sesenta y seis casos ventilados en Canadá en los que una legislación fue anulada judicialmente por violación de la Carta de Derechos, Hogg y Bushell apreciaron "que en cuarenta y cuatro de ellos (los dos tercios) el cuerpo legislativo competente modificó la ley impugnada" 74 . Estas fueron modificaciones menores que permitieron al legislador alcanzar los objetivos legales pero sin afectación constitucional. De hecho, "es raro que un defecto constitucional no se pueda corregir", y por ello es que la Carta de Derechos y su control judicial pueden 'catalizar' una conversación entre jueces y legisladores ${ }^{75}$. ¿Qué disposiciones de la Carta canadiense facilitan este diálogo? Estos autores creen que son cuatro: la sección 33 (el poder de invalidación legislativa), la sección 1 (las limitaciones razonables de libertades y derechos), las secciones 7, 8, 9 y 12 (que están calificados y por ende solo permiten afectaciones rigurosamente imparciales y razonables), y la sección 15.1 (que garantiza los derechos de igualdad) ${ }^{76}$.

La (célebre) sección 33 permite al legislador validar a priori (como revalidar a posteriori) una norma por períodos renovables de cinco años (o tan pronto como se especifique en la declaración respectiva), 'no obstante (notwithstanding, en francés indépendamment, independientemente de que)' pueda ser (o haya sido) declarada inconstitucional por afectar las libertades y los derechos consagrados en las secciones 2 y 7-15 de la Carta (libertades ideológica, religiosa, de expresión, reunión y asociación, derecho a la vida, a la integridad, a la libertad personal, a la seguridad y a no ser discriminado), excluyendo, eso sí, los derechos protegidos por las secciones 3-6 (de vota-

71 Hogg y Bushell, Diálogo, p. 19.

72 Hogg y Bushell, Diálogo, p. 20.

73 Hogg y Bushell, Diálogo, pp. 20-21.

74 Hogg y Bushell, Diálogo, p. 21.

75 Hogg y Bushell, Diálogo, p. 22.

76 Ver Hogg y Bushell, Diálogo, p. 23. 
ción y movilidad), 16-23 (de lengua) y 28 (de igualdad de género) ${ }^{77}$. Ha sido utilizada muy pocas veces, pues en Canadá -tanto por su historia de supremacía parlamentaria casi sin judicial review, como por los conflictos entre las regiones anglófonas y las francófonas- parecen convivir la resistencia política a su uso (salvo casos puntuales, sobre todo planteados en Quebec) y una cultura judicial notoriamente autorrestringida ${ }^{78}$.

La sección 1 permite "restricciones razonables (reasonable, raisonnables)", desde el punto de vista de una sociedad libre y democrática, a los derechos y libertades de la Carta $^{79}$. Tal razonabilidad de la limitación precisa, desde el fallo R. c. Oakes de 1986, cuatro condiciones: que la ley persiga un objetivo de importancia, que lo que disponga esté racionalmente conectado con tal objetivo, que no afecte un derecho o libertad más de lo necesario para alcanzar el objetivo, y que no tenga un efecto desproporcionadamente severo en quienes haya de aplicarse ${ }^{80}$. Hogg y Bushell comentan, luego de exponer algunos casos en los que algún tribunal canadiense consideró la sección 1,

77 Por su influencia, conviene citar esta sección en sus tenores originales: "33. (1) Parliament or the legislature of a province may expressly declare in an Act of Parliament or of the legislature, as the case may be, that the Act or a provision thereof shall operate notwithstanding a provision included in section 2 or sections 7 to 15 of this Charter. (2) An Act or a provision of an Act in respect of which a declaration made under this exception section is in effect shall have such operation as it would have but for the provision of this Charter referred to in the declaration. (3) A declaration made under subsection (1) shall cease to have effect five years after it limitation comes into force or on such earlier date as may be specified in the declaration. (4) Parliament or the legislature of a province may re-enact a declaration made under subsection (1).(5) Subsection (3) applies in respect of a re-enactment made under subsection (4)/ 33. (1) Le Parlement ou la législature d'une province peut adopter une loi où il est expressément déclaré que celle-ci ou une de ses dispositions a effet indépendamment d'une disposition donnée de l'article 2 ou des articles 7 à 15 de la présente charte. (2) La loi ou la disposition qui fait l'objet d'une déclaration conforme au présent article et en vigueur a l'effet qu'elle aurait sauf la disposition en cause de la charte. (3) La déclaration visée au paragraphe (1) cesse d'avoir effet à la date qui y est précisée ou, au plus tard, cinq ans après son entrée en vigueur. (4) Le Parlement ou une législature peut adopter de nouveau une déclaration visée au paragraphe (1). (5) Le paragraphe (3) s'applique à toute déclaration adoptée sous le régime du paragraphe (4)" (Constitution Act, 1982, Part I, Canadian Charter of Rights and Freedoms, Loi Constitutionelle de 1982, Partie I, Charte Canadienne des Droits et Libertés, disponible en http://www.wipo.int/wipolex/es/text. jsp?file_id=216915 [consultado el 12.11.2014]).

78 Ver Hogg y Bushell, Diálogo, pp. 24-25.

79 También conviene citarla: "1. The Canadian Charter of Rights and Freedoms guarantees the rights and freedoms set out in it subject only to such reasonable limits prescribed by law as can be demonstrably justified in a free and democratic society/1. La Charte canadienne des droits et libertés garantit les droits et libertés qui y sont énoncés. Ils ne peuvent être restreints que par une règle de droit, dans des limites qui soient raisonnables et dont la justification puisse se démontrer dans le cadre d'une société libre et démocratique".

80 Ver Hogg y Bushell, Diálogo, p. 26. 
que "la invalidez podría ser corregida por la promulgación de una nueva ley que fuera más respetuosa del derecho de la Carta y cumpliera sustancialmente con el objetivo importante", con lo cual se produce de hecho un diálogo entre el tribunal y el legislador, y el proceso democrático, aunque influenciado judicialmente, no resulta atrofiado por los jueces ${ }^{81}$.

En cuanto a los derechos calificados de las secciones 7, 8, 9 y 12, Hogg y Bushell creen que, aun si a su respecto no fuera aplicable la sección 1, sí que "admiten la posibilidad de una acción legislativa correctiva después de que una decisión judicial haya anulado una ley por violación a uno de los derechos", lo que otra vez muestra, dicen, cómo es que no solo es posible sino que de hecho ha ocurrido entre las cortes y el legislador un "diálogo productivo" 82 .

En cuanto a los derechos de igualdad de la sección 15, que prohíben discriminar por motivos de raza, etnia, nacionalidad, color, religión, sexo, edad o discapacidad física o mental, Hogg y Bushell dicen que normalmente las leyes consideradas discriminatorias por un tribunal han llevado a respuestas legislativas más inclusivas, sin descartar algunos casos en que el legislador ha optado por excluir o reducir un beneficio estatal ("después de todo, no se trata del derecho del demandante a un cheque del gobierno, sino de un derecho a la igualdad, que la Corte ha ratificado" ${ }^{83}$ ).

Claro es, según Hogg y Bushell, que el diálogo no se produce y la Corte Suprema mantendrá la última palabra (a) cuando la sección 1 no sea aplicable por ser los derechos tan específicos que no admitan restricciones razonables, (b) cuando la declaración de inconstitucionalidad afecte al objetivo mismo (y no solo a los efectos) de una ley, y (c) cuando las fuerzas políticas con representación parlamentaria no logren responder a una decisión judicial con carácter constitucional ${ }^{84}$. Sin embargo, y por alguna de las cuatro vías antes mencionadas, el diálogo en general sí se produce, incluso con cierta inmediatez temporal, cosa que se aprecia en los preámbulos legales y en las cláusulas de propósito de leyes ${ }^{85}$. Y aun cuando un tribunal no invalide por inconstitucional una ley, puede haber cierto diálogo, como en el caso Thibaudeau c. Canada de 1995, en el que, luego de que un tribunal desestimara una pretensión de inconstitucionalidad, el parlamento llevó a cabo una modificación legislativa: tal respuesta legislativa "enfatiza que es un error considerar que la Carta les da a tribunales no electos un poder de veto por sobre la voluntad democrá-

81 Ver Hogg y Bushell, Diálogo, pp. 26-29.

82 Hogg y Bushell, Diálogo, pp. 29 y 32 (ver casos en pp. 29-31).

83 Hogg y Bushell, Diálogo, p. 33.

84 Ver Hogg y Bushell, Diálogo, pp. 33-38.

85 Ver Hogg y Bushell, Diálogo, pp. 38-46. 
tica de los órganos legislativos competentes. Los legisladores canadienses no son indiferentes a las preocupaciones por la igualdad y por las libertades civiles que se plantean en los casos de la Carta, y no siempre esperan a que un tribunal los 'obligue' a modificar sus leyes para mostrarse dispuestos a considerar leyes más justas, menos restrictivas o más inclusivas [...] El diálogo de la Carta puede continuar fuera de los tribunales" $"$. Así, pues, aunque los tribunales no sean democráticamente responsables y a veces anulen las leyes del órgano provisto de legitimidad democrática, "casi siempre" este tiene la posibilidad de responder a los jueces, con lo cual el objetivo social y económico -democráticamente elaborado- "será alcanzado de todas formas, aunque con algunas garantías nuevas que protejan la libertad y los derechos individuales" $" 87$

Lo que Hogg y Bushell muestran, en todo caso, es que el canadiense es un modelo en el que el diálogo entre cortes y parlamento es no solo posible, sino que en los hechos se ha desarrollado con cierta fluidez y persistencia ${ }^{88}$. Pero lo que no alcanzan a asegurar es que el de Canadá sea un modelo de constitucionalismo débil. Y es que, pese al influjo normativo y político de la notwithstanding clause (aun en los mismos Estados Unidos), según opinión prácticamente unánime la sección 33 de la Carta apenas se ha aplicado y casi parece haber caído en desuetudo ${ }^{89}$. De ahí que se haya dicho, no tanto por

86 Hogg y Bushell, Diálogo, p. 47.

87 Hogg y Bushell, Diálogo, pp. 47-48.

88 Ambos autores, en compañía de WADE WRIGHT, han actualizado y defendido las tesis de este texto diez años después: Charter Dialogue Revisited: or 'much ado about metaphors'. Osgoode Hall Law Journal, 45/1, 2007, pp. 1-65, concluyendo -cito el final de su abstract- "that the dialogue phenomenon is alive and well and that the critique of the original article is largely "much ado about metaphors"'. En el mismo número de esta revista, dedicado al diálogo respecto de la Carta canadiense de derechos y libertades diez años después del seminal artículo de HoGG y BUSHELl, hay varios artículos dedicados a comentar el de HOGG, BUSHELl y WRIGHT (pp. $67-$ 191), incluyendo la réplica de estos a aquellos (pp. 193-202). Todo hay que decirlo: no hay, sin embargo, unanimidad respecto a las virtudes dialógicas del modelo canadiense; en contra, ver por ejemplo LiNARES, Diálogo, pp. 515-516.

89 Para más detalles y perspectivas más recientes sobre el casi desuso de la notwithsanting clause, ver DAVID SNOw. Notwithstanding the Override: Path Dependence, Section 33, and the Charter. Innovations: A Journal of Politics, 8/1, 2009, pp. 1-15 (disponible en http://www. ucalgary.ca/innovations/volume8/snow [consultado el 12.11.2014]); ADAM DODEK. A Tale of Two Maps: The Limits of Universalism in Comparative Judicial Review. Osgoode Hall Law Journal, 47/2, 2009, p. 304; y FedERICO DE MONTALVO. Las cláusulas notwithstanding y override del constitucionalismo canadiense. Teoría y Realidad Constitucional, 30, 2012, esp. pp. 394-404. No hay unanimidad, sin embargo, respecto del desuso de la cláusula: "es un elemento central del modelo Commonwealth, pues [...] este modelo de constitucionalismo tiene que ver más con el procedimiento que con el resultado. La promesa del modelo se cumple en la medida en que la desobediencia del legislativo a las decisiones judiciales es una 'posibilidad política 
el examen del texto constitucional cuanto por la consideración del proceso político, que el canadiense ha dejado de ser un modelo de revisión judicial débil para volverse de facto un modelo de revisión judicial fuerte, uno en el cual los tribunales, especialmente la Corte Suprema, mantienen la última palabra institucionalmente hablando acerca de cuestiones de derechos ${ }^{90}$. Por lo mismo, conviene aludir a otros modelos realmente existentes cuyo constitucionalismo débil sí sea inequívoco. Es el caso británico y el neozelandés, cuyas similitudes permitirán abordarlos comparada y brevemente.

\section{Los modelos británico y neozelandés}

En el Reino Unido, tras la aprobación en 1998 y la entrada en vigencia en 2000 de la Human Rights Act (= HRA), lo que hay es un modelo ya sin la soberanía parlamentaria tradicional, pero que tampoco adopta ninguna forma de revisión judicial fuerte ni de rigidez constitucional ${ }^{91}$. La sección 3(1) de la HRA dispone que la legislación debe leerse y aplicarse por los jueces de manera compatible con los derechos allí protegidos (que, en su mayoría, son los de la Convención Europea de Derechos Humanos, de 1950). Los jueces, sí, pueden alterar el sentido literal de las leyes incluyendo o excluyendo expresiones con el fin de hacerlas compatibles con los derechos protegidos, lo que -se ha dicho- sería "una técnica alternativa de invalidación judicial"92.

realista"': MELERo, Vandalismo, cit., p. 34. Siempre, claro, que el legislador, retrasando la invalidación judicial de una ley mediante la cláusula notwithstanding, sea capaz de producir una reforma constitucional, pues en Canadá -según la sección 52- la Constitución es ley suprema, los tribunales son los que han de interpretarla y una ley ordinaria que la contradiga no tiene efecto: Melero, Vandalismo, cit., pp. 31 y 34.

90 Ver Rivka Weill. Commonwealth Model, pp. 128-129, 148 y 167, y Mark Tushnet. The Charter's Influence around the World, Osgoode Hall Law Journal, 50/3, 2013, p. 542. En todo caso, se hallan en Canadá -como en otras jurisdicciones del modelo de la Commonwealthcasos de activismo judicial por vía interpretativa, esto es, mediante la ejecución de interpretaciones abiertamente constructivas que pretenden despejar inconsistencias legislativas para con los derechos y libertades (con lo cual, dicho sea de paso, se dispone de otro argumento para calificar al canadiense como un modelo de revisión judicial fuerte que distorsiona doblemente la razón pública: otorgando un papel preeminente y autorizado a los jueces cuando se trata de interpretar los derechos constitucionales y volviendo este razonamiento judicial en un paradigma de razonamiento aun para los debates parlamentarios sobre derechos). por ejemplo, a propósito de la protección de derechos de homosexuales, ver Melero, Vandalismo, cit., pp. 34-41.

91 También sigo, en este resumen del modelo británico, a LiNAREs, Diálogo, cit., pp. 501503 y 516-517, y a MELERO, Vandalismo, cit., pp. 31 y 33-34. Para mayores detalles, ver ELIZA KaCZYNSKA-NAY. The Human Rights Act 1998: The UK 'Dialogue' Model of Human Rights Protection. National Europe Centre Briefing Paper Series 1/1, 2009, pp. 1-21; GARDBAUM. New Commonwealth, cit., pp. 156-203.

92 Melero, Vandalismo, cit., p. 33. 
La sección 4 de la HRA agrega que, de ser una ley incompatible con los derechos, los jueces (nótese: solo los previstos en la sección 4(5)) podrán dictar una declaración de incompatibilidad que no anula ni invalida a la ley (la legislación primaria, se entiende, no la subordinada, que sí puede ser dejada sin efecto por entrar en conflicto con los derechos). Además, según la sección 19 de la HRA, los ministros del gabinete deben justificar la compatibilidad de los proyectos de ley con los derechos protegidos y, en caso de incompatibilidad, de que continuarán adelante con dichos proyectos. Hay en el Parlamento, conviene decirlo, un Comité Conjunto sobre Derechos Humanos (Joint Comittee on Human Rights) que ha de informar sobre la compatibilidad (y las dudas a su respecto) de los proyectos de ley para con los derechos protegidos. En este caso, el de incompatibilidad de una ley, existe tanto una acción remedial (remedial action) que provee un procedimiento de enmienda veloz de la ley impugnada judicialmente, activable por el ministro que sea competente y que ha de ser finalmente aprobada parlamentariamente dentro de los 120 días siguientes a su presentación, como un procedimiento de emergencia (fast-track procedure), también activable por el ministro que sea competente y que permitirá la entrada en vigencia de la enmienda inmediatamente, sin aprobación parlamentaria, aunque en tal caso el Parlamento ha de ratificarla dentro de 120 días, sin lo cual perderá vigencia de ahí en adelante (aunque no retroactivamente). Así, la ley que ha sido judicialmente declarada incompatible con los derechos sigue siendo válida y teniendo plena aplicabilidad jurídica, al menos hasta que no sea derogada o modificada parlamentariamente. El Parlamento, pues, mantiene la última palabra, tanto en el sentido de que ante una declaración judicial de incompatibilidad puede modificar la HRA (subsanando así tal inconsistencia), como en el de que ante una declaración judicial de incompatibilidad puede tomar la opción de no hacer nada, con lo cual hace predominar pura y simplemente su punto de vista frente a los jueces.

El modelo neozelandés es semejante ${ }^{93}$. Hay una New Zealand Bill of Rights Act de 1990 (= NZBRA) que precisamente intenta combinar la protección de los derechos fundamentales con la entrega de la última palabra, por eventual afectación de ellos, al legislador. La sección 5 de la NZBRA es casi una copia de la 1 de la Carta canadiense de 1982 . Y las secciones 4 y 7 establecen precisos requerimientos: se obliga al gobierno a revisar la constitucionalidad de todos sus proyectos antes de enviarlos al parlamento (aquí, a diferencia del Reino Unido, es el ministro de justicia el que debe ponderar la compatibilidad de los proyectos de ley con los derechos protegidos), y al legislador a discutir acer-

93 Otra vez sigo los resúmenes que ofrecen LinAREs. Diálogo, cit., p. 504, y Melero. Vandalismo, cit. pp. 30-31 y 33-34. Para mayores detalles, ver GARdBAum. New Commonwealth, cit., pp. 129-155. 
ca de posibles vulneraciones legales de derechos y a declarar explícitamente cuáles son las razones que avalarían tales vulneraciones. Además, la sección 6 de la NZBRA manda a los jueces interpretar las leyes de modo compatible con ella misma, pero - por mandato de la sección 4- sin poder invalidarlas en caso alguno. La NZBRA no incluye una declaración judicial de incompatibilidad entre leyes y derechos, pero a partir del caso Moonen v. Film and Literature Board of Review del año 2000, la New Zealand Court of Appeals (entonces el supremo tribunal neozelandés, papel que desde el año 2004 desempeña la Corte Suprema de Nueva Zelanda) ha interpretado la mencionada sección 6 como comprehendiendo la facultad de dictar -según el molde británico- declaraciones de incompatibilidad. Mas, tales declaraciones de incompatibilidad no afectan directamente a la legislación, de modo que el legislador no tendría en rigor una obligación de reparar los defectos constitucionales judicialmente indicados, aunque sí tendría que asumir los costos políticos de promulgar una ley que afectara derechos ${ }^{94}$.

Con sus méritos, sobre todo el de reservar al representante democrático la última palabra institucional cuando hay conflictos entre derechos y leyes, los problemas dialógicos de justificación de estos dos modelos saltan a la vista. Por una parte, para evitar declaraciones de incompatibilidad que el legislador puede desatender, el juzgador puede optar por interpretaciones de la ley que fuerzan un sentido diverso del literal, soslayando así el ejercicio de argumentar directa y explícitamente contra las razones parlamentarias. Y cuando el juez sí emite una declaración de incompatibilidad, lo que abriría entonces el diálogo, esta vía puede verse frustrada en la medida en que el parlamento no está en general obligado a responder las razones judiciales de la incompatibilidad (salvo en el procedimiento de enmienda rápida, cuyo uso es de discreción del ministro respectivo).

\section{Modelos puramente teorizados}

La otra alternativa es la de diseñar prospecciones puramente ideales que remedien los problemas que aquejan a los modelos canadiense, inglés y neozelandés, los cuales "o dan margen para un genuino diálogo pero depositan la última palabra en la cortes [sería lo que ocurre en Canadá], o bien dan primacía al Congreso pero no dan margen para un genuino diálogo [sería lo que ocurre

94 Ver Mark Tushnet. Revisión judicial dialógica. Trad. M. Sterzovsky y G. IezZi. En: R. Gargarella, comp. Por una justicia dialógica. El Poder Judicial como promotor de la deliberación democrática. Buenos Aires, Siglo XXI Editores, 2014, pp. 114-115, mencionando el caso BAIGENT (Simpson c. Attorney-general). 
en el Reino Unido y en Nueva Zelanda]"95. Una judicatura constitucional no hipertrofiada, y que además dialogue con una legislatura que mantenga la última palabra en materia de derechos constitucionales (en el sentido, repito, de tener la potestad de dictar la regla de cierre en estas materias), pero siempre bajo la exigencia de justificar sus decisiones cuando estas se apartan de los criterios judiciales: tal es el propósito de dichas idealizaciones.

Una propuesta así teorizada es la de H. Spector, quien propone un sistema híbrido, tanto con judicial review (concentrada o difusa, abstracta o concreta) como también con un mecanismo democrático de control constitucional basado en la institución de un jurado constitucional ${ }^{96}$. Veámoslo sucintamente. Para Spector, "los ciudadanos deberían tener el derecho opcional a que sus reclamos relacionados con derechos sean resueltos por un jurado constitucional" ${ }^{\prime 97}$. Se basa en los juicios griegos graphe paranomon y graphe nomon me epitedeion theinai, y en los de anulación propiciados por Hobbes y Spooner ${ }^{98}$. Un jurado constitucional podría defender tanto los derechos morales procedimentales como la igual libertad política. Y aunque puede tener dificultades de cara a proteger minorías de mayorías, sí que resulta preferible allí donde los jueces son deferentes ante los representantes políticos y donde unos y otros "tienen intereses y preocupaciones compartidas" ${ }^{99}$. Los ciudadanos, en este modelo, pueden optar entre un tribunal colegiado que haga judicial review y un jurado constitucional con igual propósito. Los derechos morales, dice Spector, incluyen tanto derechos sustantivos como derechos procedimentales, y en esta última faceta, la procedimental, incluyen tanto un ingrediente de reclamo como uno de respuesta ${ }^{100}$. Estos derechos morales procedimentales "constituyen un sistema de justicia procedimental pura". Así, pues, un buen diseño institucional debe satisfacer la posibilidad de reclamar ("expresar sus agravios mediante su propia voz") y la expectativa de obtener respuesta "deliberada e imparcial" 101 . A esto se debe la existencia de tribunales colegiados que ejercen control de constitucionalidad. Sin embargo, estos tribunales tienden a lesionar la igual libertad política. De ahí que Spector explore la alternativa de simultanearlo con un jurado al que se puede acudir opcionalmente para

95 LinARes, Diálogo, cit., p. 488.

96 Ver H. SPECTOR. Un sistema democrático de control constitucional. En: R. GARGARELlA, comp. Por una justicia dialógica. El Poder Judicial como promotor de la deliberación democrática. Buenos Aires, Siglo XXI Editores, 2014, p. 193.

97 Spector, Sistema, p. 195.

98 Ver SPECTOR, Sistema, pp. 195 y 199-201.

99 SPECTOR, Sistema, p. 195.

100 Ver SPECtor, Sistema, pp. 202 y 196.

101 SPECTOR, Sistema, p. 198. 
que controle la constitucionalidad de las leyes, derogando las que "no satisfagan el test basado en derechos", satisfaciendo así las facetas de reclamo y de respuesta: "la nulidad procedería caso por caso. Así, asumo que los jurados, al igual que los tribunales en el sistema de control concreto, operan en casos particulares" ${ }^{102}$. Spector cree que estos jurados constitucionales pueden funcionar en la práctica como asambleas compuestas por más de 500 miembros, que respetarían plenamente la igual libertad política al designarse sus miembros por sorteo, siendo tanto o más capaces de otorgar respuestas imparciales "que un puñado de jueces designados", así como de producir respuestas (sentencias) razonadas o deliberadas, estructurando pues deductivamente la relación entre los fundamentos (premisas) constitucionales, interpretativos y fácticos, y la conclusión ${ }^{103}$.

El problema con este diseño es que sigue amenazando con cierto activismo $y$, respecto de su idea de un jurado constitucional, que no pretende una revisión judicial dotada de algún valor epistémico y cuyos resultados sustantivos probables complementen y no reproduzcan la deliberación democrática. Justo por considerar institucionalmente estos criterios, sería preferible tomar en cuenta un modelo ideal como el de S. Linares:

... mi propuesta delinea un esquema en el cual, en primer lugar, los jueces inferiores a la Corte Suprema (o Tribunal Constitucional) solo pueden pronunciar declaraciones de incompatibilidad (respecto de las leyes contemporáneas). En segundo lugar, autoriza a las Cortes Supremas [o Tribunal Constitucionales] a declarar la invalidez de una ley o acto normativo con carácter general. Un sistema como este permite que las declaraciones de incompatibilidad de los jueces inferiores funcionen como un mecanismo de alerta, que le advertiría al Congreso que, si el caso llega al alto tribunal, la decisión política tiene probabilidades de ser vetada. De este modo, el Congreso tiene tiempo para ensayar otras políticas alternativas o comenzar a articular una defensa razonada de la política cuestionada. Además, bajo este sistema el Congreso tiene incentivos para contestar porque sabe que, si no obra de manera responsable, el alto tribunal puede terminar vetando la decisión política. Junto con ello, la Corte debería disponer de recursos para mitigar las confrontaciones con el Congreso. En ese sentido, las declaraciones de inconstitucionalidad 'con plazo de espera' o efecto retardado (esto es, sentencias que producen efectos invalidatorios después de transcurrido cierto tiempo) parecen sumamente apropiadas. Por último, y para salvar la autoridad final de las Legislaturas, cabe agregar que, en el supuesto de que la Corte opte por invalidar la norma con carácter general, el Congreso puede echar mano de una suerte de cláusula 'override' para hacer valer su postura. Sin embargo, la invocación de

102 SPECTOR, Sistema, p. 201.

103 SPECTOR, Sistema, pp. 202-205. 
esa cláusula debería cumplir con ciertos recaudos. Así, cabría estipular la obligación del Congreso de responder en una audiencia pública a todos los argumentos vertidos por la Corte Suprema, incluso a los basados en derechos. Después de esta audiencia, una vez oídas todas las posturas, el Parlamento podría volver a debatir la cuestión y someterla a votación. Por último, cabría estipular que el uso de esta cláusula tenga efectos temporales, es decir, que la decisión del Congreso que revalida una norma previamente declarada inconstitucional por la Corte tenga vigencia hasta la formación de una nueva Legislatura electa, que estaría obligada a ratificar la decisión del Congreso anterior. Sin duda, un sistema como este no garantiza en absoluto el surgimiento de un genuino diálogo, pero ofrece incentivos para que la deliberación sea más probable, a la par que le deja la última palabra institucional al Congreso ${ }^{104}$.

Este modelo, creo, tiene el mérito de tratar de salvar la deliberación democrática entre cortes y legisladores, tanto por lo que tiene de diálogo (al forzar la argumentación no solo del juez sino también, y precisamente, del legislador y aun del administrador), cuanto por lo que tiene de democrático (al otorgar la última palabra al órgano representativo). Dispositivos como los que incluye hacen al menos probable que el legislador, pudiendo finalmente hacer prevalecer su voluntad, tenga que involucrarse en un diálogo razonado que lo fuerce a escuchar la argumentación de los jueces, a responderla públicamente con una batería de argumentos tan apropiados como pueda, e incluso a confirmar luego de una elección parlamentaria su propia revalidación de aquella legislación que haya sido invalidada judicialmente.

A mi modo de ver, convendría considerar estas y otras variantes de constitucionalismo débil, dialógico y últimamente democrático. Después de todo, ¿forma parte de nuestro consenso constitucional un poderoso control judicial abstracto (tan reciente, en realidad)? ¿No sería algún modelo débil y dialógico perfectamente compatible con los elementos históricamente decisivos de nuestro sistema jurídico? Por lo demás, ¿cómo se introdujo en Chile la inaplicabilidad por inconstitucionalidad si no fue siguiendo a un sistema jurídico tan distinto del nuestro como el norteamericano -y cómo no se advierte que otros países latinoamericanos, como Argentina, Brasil y México, han emulado el modelo estadounidense de judicial review? Si nada menos que en el Reino Unido la añosa supremacía parlamentaria según el modelo de Westminster acaba de ser significativamente modificada acogiéndose cierto control judicial -aunque débil- de constitucionalidad, ¿es que la forma sumamente fortificada del modelo kelseniano de tribunal constitucional que se adoptó

104 LINARES. Justicia dialógica interinstitucional: de lege ferenda y de lege lata, cit., pp. 188-189, que es un resumen de la propuesta desplegada en LiNAREs, Diálogo, cit., pp. 521-523. 
entre nosotros, tras discusiones más bien breves y poco sensibles al estado de la cuestión en la teoría constitucional y democrática contemporáneas, no podría ser también precisamente debilitada? Pues, aunque las instituciones sean en cada caso sensibles a la historia política, a la tradición jurídica y a la cultura judicial, son justamente ideas históricas -con pasado, pero también con futuro- las que sirven como parámetros para evaluar las pretensiones y la efectividad de los diseños institucionales.

\section{PERSPECTIVAS}

En síntesis, la actual discusión política y constitucional chilena ofrece no un consenso, pero sí una cierta tendencia transversal que converge en favorecer cuando menos una significativa disminución de las facultades del TC. La discusión al respecto, sin embargo y salvo alguna excepción, sigue siendo magra. Sobre todo, no contempla aún la posibilidad de rediseñar el TC para que ejecute un control de constitucionalidad de la actividad parlamentaria y administrativa más débil que lo que es usual en la judicial review estadounidense y en modelos kelsenianos como el alemán y el español. De esta manera, primero, la última palabra no sería la de los jueces constitucionales, sino la del órgano dotado de legitimidad democrática, como ya ocurre en otros sistemas jurídicos realmente existentes y como bien pudiera ocurrir según modelos por ahora puramente teorizados. Y, segundo, así su intervención revisora se justificaría sobre todo por su valor epistémico y, consiguientemente, el valor de sus resultados compensaría su intrínseco disvalor democrático, forzando precisamente con la sofisticación filosófica y jurídica de sus argumentos a que el representante democrático justifique el ajuste constitucional y iusfundamental de sus leyes, decretos y reglamentos según exigentes estándares de razonamiento.

Esta sofisticación que cabe esperar del TC supone en los jueces constitucionales chilenos una actitud intelectualmente más desenvuelta y responsable. Pues el estándar de acuerdo con el cual habría que juzgar a un juez constitucional es, creo, el de Rawls: "la razón pública es la única razón de que se vale el tribunal [supremo o constitucional]", lo que es tanto como decir que este órgano se justifica si y solo si es "palmaria y visiblemente criatura de la razón [pública]"105. Por lo mismo, si cuando los jueces se enteraron de la importancia del análisis sociológico, económico o literario para el pensamiento jurídico, no se transformaron por ello en economistas ni en expertos en sociología o literatura, pero sí se tuvieron que formar con mayor sensibilidad en dichos

105 RAWLs, Liberalismo, p. 270. 
ámbitos disciplinarios, así también tendría que suceder con los niveles de rigor filosófico exigibles para tomar parte en la adjudicación constitucional, la cual requiere de sinceridad ante un trabajo con conceptos filosóficos que inevitablemente se entreverarán cuando conozcan y juzguen casos constitucionales, así como de realismo "sobre el duro trabajo que afrontarán para cumplir la promesa de esos conceptos" ${ }^{106}$. Solo jueces constitucionales filosóficamente sofisticados por una más afinada capacidad de juicio político y jurídico, supongo yo, estarán en condiciones institucionales de cumplir con su función principial, argumentativa o epistémica y, así, exhibir el valor instrumental de su tarea de producir resultados sustantivamente valiosos para el proceso democrático y exigir de los representantes electos $-\mathrm{y}$ a toda su maquinaria técnica-razones convincentes y precisas que les permitan sortear esas declaraciones judiciales de incompatibilidad e incluso de invalidez que toman como patrón de juicio a las normas constitucionales y a los derechos fundamentales. Lo cual, dicho sea antes de terminar, haría estrictamente necesario que los jueces constitucionales chilenos sean seleccionados bajo un escrutinio público, riguroso (no opaco y vulgarizado por el partisanismo) y según un proceso gobernado por requisitos exigentes de elegibilidad (y que sea homenajeado, no burlado, por la cultura política y jurídica). Es cierto que en Chile aún no se ha constituido una comunidad jurídica de expertos y jueces, es decir, tanto una dogmática de juristas académicos como una jurisprudencia judicial que sean equiparables a las de otras culturas, pero también lo es que el panorama parece actualmente más promisorio que antaño. Y es que si resulta delicado el cometido que se les entrega a los jueces constitucionales, aun bajo formas débiles y dialógicas, parece simplemente indefendible que tal actividad sea desempeñada por quienes no tengan otra credencial que la abogacía, la operación política, el mero desempeño de una asesoría parlamentaria o presidencial.

\section{BIBLIOGRAFÍA}

Arendt, Hannah (2003). Conferencias sobre la filosofía politica de Kant. Trad. C. Corral. Barcelona, Paidós.

AREndt, Hannah (2008). Eichmann en Jerusalén. Trad. C. Ribalta. Barcelona, DeBolsillo.

ATRIA, FERNANDO (2001). Inaplicabilidad y coherencia: contra la ideología del legalismo. Revista de Derecho. Universidad Austral de Chile (12/1) pp. 119-156.

Atria, FERnANDo (2008). El TC como tercera cámara. La Segunda (9.09.2008).

106 Como recuerda Dworkin, Jueces, p. 29. 
Atria, Fernando (2013a), Veinte años después. Neoliberalismo con rostro humano. Santiago de Chile, Catalonia.

Atria, Fernando (2013b), La Constitución tramposa. Santiago de Chile, Lom.

ATRIA, FERNANDO (2014). Legislación, jurisdicción, administración. En: P. GREZ et al. (coords.), Una vida en la Universidad de Chile. Celebrando al Profesor Antonio Bascuñán Valdés. Santiago de Chile, Legal Publishing (2014) pp. 77-185.

BAYÓN, JUAN CARLOS (2009). ¿Necesita la república deliberativa una justificación epistémica? Diritto \& questioni pubbliche, (9) pp. 189-228.

BAYÓN, JUAN CARLOS (2010). Democracia y derechos: problemas de fundamentación del constitucionalismo. En: CARBOnell, M. y GARCía, L., coord. El canon neoconstitucional. Madrid, Trotta, pp. 285-355.

BILSKY, L. (1996). When actor and spectator meet in the courtroom: Reflections on Hannah Arendt's concept of judgment. History and Memory (8/2) pp. 137-173.

Carroll, Royce y Tiede, Lydia (2011). Judicial Behavior on the Chilean Constitutional Tribunal. Journal of Empirical Legal Studies (8/4) pp. 856-877.

Colón-Ríos, Joel y Hutchinson, Allan (2011). "Constituciones duraderas. Una crítica democrática". Trad. J. PABón y K. Stone. Anuario de Derecho Público. Universidad Diego Portales (2) pp. 437-460.

Colón-Ríos, Joel (2012). Weak Constitutionalism: Democratic legitimacy and the question of constituent power. New York, Routledge.

Colón-Ríos, Joel (2014). A new typology of judicial review of legislation. Global Constitutionalism (3/2) pp. 143-169.

Couso, JAVIer y Coddou, Alberto (2010). La naturaleza jurídica de la acción de inaplicabilidad en la jurisprudencia del Tribunal Constitucional: un desafío pendiente. Estudios Constitucionales. Universidad de Talca (8/2) pp. 389-430.

DixON, RosALIND (2011). Weak-form judicial review and american exceptionalism. Chicago Public Law and Legal Theory. Working Paper 348.

DixOn, Rosalind (2014). Para fomentar el diálogo sobre los derechos socioeconómicos. Una nueva mirada acerca de las diferencias entre revisiones judiciales fuertes y débiles. Trad. H. Salas. En: Gargarella, R., comp. Por una justicia dialógica. El Poder Judicial como promotor de la deliberación democrática. Buenos Aires, Siglo XXI Editores, pp. 51-103.

DodeK, AdAm (2009). A tale of two maps: The limits of universalism in comparative judicial review. Osgoode Hall Law Journal (47/2) pp. 287-316.

DWORKIn, RONALD (2012). El foro de los principios. En: Una cuestión de principios. Trad. V. Boschiroli. Siglo XXI Editores, pp. 53-102.

DWORKIN, RonALD (2010). ¿Deben nuestros jueces ser filósofos? ¿Pueden ser filósofos? Trad. L. GARCíA. Isonomía (32) pp. 7-29. 
Dworkin, Ronald (2014). Justicia para erizos. Trad. H. Pons. México, FCE.

Ely, John Hart (1980). Democracy and Distrust. A Theory of Judicial Review. Cambridge (Mass)/London, Harvard University Press.

Fermandois, A (2006/2010). Derecho Constitucional Económico. T. 1, Garantías económicas, doctrina y jurisprudencia. T. 2, Regulación, tributos y propiedad. Santiago de Chile, Universidad Católica de Chile.

Figueroa, Dante (2013). Constitutional review in Chile revisited: A revolution in the making. Duquesne Law Review (51) pp. 387-419.

Frei, EduARdo et al. (1970). Reforma Constitucional de 1970. Santiago de Chile, Editorial Jurídica.

García, J. F. (2014). Minimalismo e incrementalismo constitucional. Revista Chilena de Derecho (41/1) pp. 267-302.

GARCíA, J. F. (2014). TC en momentos de cambio. La Tercera (14.08.2014).

Gardbaum, Stephen (2013). The New Commonwealth Model of Constitutionalism. Theorie and Practice, Cambridge, CuP.

GARgarella, R. (2014). El nuevo constitucionalismo dialógico frente al sistema de los frenos y contrapesos. En: R. Gargarella, comp. Por una justicia dialógica. El Poder Judicial como promotor de la deliberación democrática. Buenos Aires, Siglo XXI Editores (2014) pp. 119-158.

Hogg, Peter; Bushell, Allison y Wright, Wade (2007). Charter dialogue revisited: Or 'much ado about metaphors'. Osgoode Hall Law Journal (45/1) pp. 1-65.

Hogg, Peter y Bushell, Allison (2014). El diálogo de la Carta entre los tribunales y las Legislaturas (o quizá la Carta de Derechos no sea algo tan malo después de todo). Trad. S. SERESEVSKy. En: R. GARgarella, comp. Por una justicia dialógica. El Poder Judicial como promotor de la deliberación democrática. Buenos Aires, Siglo XXI Editores, pp. 17-49.

JoRdÁn, T. (2008). Algunos comentarios a la sentencia del TC n. ${ }^{\circ}$ 976/2008. Nomos. Revista de Derecho de la Universidad Viña del Mar (2) pp. 263-274.

KacZYnska-NAY, Elisa (2009). The Human Rights Act 1998: The UK 'Dialogue' Model of Human Rights Protection. National Europe Centre Briefing Paper Series (1/1) pp. 1-21.

Kant, Immanuel (1992). Crítica de la facultad de juzgar. Trad. P. Oyarzún. Caracas, Monte Ávila Editores.

Kelsen, Hans (1928). La garantie juridictionnelle de la Constitution (La Justice constitutionnelle). Revue de Droit Publique et de la Science Politique en France et a l'Étranger (35) pp. 197-257.

Kelsen, Hans (2009). ¿Quién debe ser el defensor de la Constitución? (1931). En: La polémica Schmitt/Kelsen sobre la justicia constitucional. Trad. M. SÁnCHEZ y R. BRIE. Madrid, Tecnos, pp. 289-366. 
LANGFORD, M., ed. (2013). Teoría y jurisprudencia de los derechos sociales. Tendencias emergentes en el derecho internacional y comparado. Trad. C. MoRALES. Bogotá, Universidad de los Andes.

LINARES, S. (2008). El diálogo democrático entre las cortes y las instituciones representativas. Revista mexicana de sociología (70/3) pp. 487-539.

LiNARES, S. (2013). Justicia dialógica interinstitucional: de lege ferenda y de lege lata. Trad. S. Seresevsky. En: R. Gargarella, comp. Por una justicia dialógica. El Poder Judicial como promotor de la deliberación democrática. Buenos Aires, Siglo XXI Editores, 2014, pp. 187-192.

LoRenzetti, R. (2014). Las audiencias públicas y la Corte Suprema. En: R. GARGARELla, comp. Por una justicia dialógica. El Poder Judicial como promotor de la deliberación democrática. Buenos Aires, Siglo XXI Editores, pp. 345-354.

Marinoni, Luis; Pérez, Álvaro y Núñez, Raúl (2010). Fundamentos del proceso civil. Hacia una teoría de la adjudicación. Santiago de Chile, Abeledo Perrot.

MARSHALL, P. (2010). Tabla de factores de la Ley de Isapres y derechos fundamentales (Tribunal Constitucional). Revista de Derecho. Universidad Austral de Valdivia (23/2) pp. 247-264.

MARTínEZ Estay, J. (2008). Los derechos sociales: una reflexión a propósito de la sentencia rol 976 del TC. Nomos. Revista de Derecho de la Universidad Viña del Mar (2) pp. 275-290.

Melero, Mariano (2013/2014). La interpretación constructiva en el constitucionalismo commonwealth: ¿activismo o vandalismo judicial? Eunomía (5) (2013/2014) pp. 27-49.

De Montalvo, Federico (2012). Las cláusulas notwithstanding y override del constitucionalismo canadiense. Teoría y Realidad Constitucional (30) pp. 387-409.

NAVARRo, EnRiQue (2011). El control de constitucionalidad de las leyes en Chile (1811-2011). Cuadernos del Tribunal Constitucional (43) 152 pp.

NúÑEZ, J. I. (2014). Pensando en la justicia constitucional de una nueva constitución: 'cada paloma es libre de ser el hipopótamo que quiera'. En: H. TóRTORA y T. JORDÁN, coords. Estudios para una nueva constitución. Santiago de Chile, Metropolitana, pp. 691-704.

RaWls, John (2013). El liberalismo político. Trad. A. Domènech. Barcelona, Crítica.

Rodríguez, C. (2014). El activismo dialógico y el impacto de los fallos sobre derechos sociales. En: R. Gargarella, comp. Por una justicia dialógica. El Poder Judicial como promotor de la deliberación democrática. Buenos Aires, Siglo XXI Editores, pp. 211-244.

Rosenmüller, S. (2013). Der Ort des Rechts. Gemeinsinn und richterliches Urteilen nach Hannah Arendt. Baden-Baden, Nomos.

Ruiz Miguel, Alfonso (2009). Lo no deliberable de la democracia deliberativa. Diritto \& questioni pubbliche (9) pp. 347-356.

RuIZ, E. (2012). La excepción constitucional australiana. El debate sobre la protección jurídica de los derechos y el modelo del diálogo institucional. Revista española de derecho constitucional (95) pp. 95-138. 
Shapiro, S. (2014). Legalidad. Trad. D. PAPAYAnnis y L. RAmírez. Barcelona, M. Pons.

SNOw, DAVID, (2009). Notwithstanding the Override: Path Dependence, Section 33, and the Charter. Innovations: A Journal of Politics (8/1) pp. 1-15. Disponible en http://www. ucalgary.ca/innovations/volume8/snow [consultado el 12.11.2014].

SPECTOR, H (2014). Un sistema democrático de control constitucional. En: R. GARGARELLA, comp. Por una justicia dialógica. El Poder Judicial como promotor de la deliberación democrática. Buenos Aires, Siglo XXI Editores, pp. 193-208.

SOlARI, EnZo (2012). Un constitucionalismo inocuo. Estudios constitucionales (10/2) pp. 455-510.

Tushnet, MARK (2009). Weak Courts, Strong Rights: Judicial Review and Social Welfare Rights in Comparative Constitutional Law. Princeton, Princeton University Press.

Tushnet, Mark (2013). The Charter's Influence Around the World. Osgoode Hall Law Journal (50/3) pp. 527-546.

Tushnet, Mark (2014). Revisión judicial dialógica. Trad. M. Sterzovsky y G. Iezzi. En: R. Gargarella, comp. Por una justicia dialógica. El Poder Judicial como promotor de la deliberación democrática. Buenos Aires, Siglo XXI Editores, pp. 105-116.

VIERA, CH (2008). La emergencia de los derechos sociales en el sistema constitucional chileno. Comentario de la sentencia del TC relativa a la Ley de Isapres: de la mera expectativa al derecho en forma. Nomos. Revista de Derecho de la Universidad Viña del Mar (2) pp. 291-305.

Viera, CH (2013). Libre iniciativa económica y Estado social. Análisis al estatuto de la libertad de empresa en la Constitución chilena. Santiago de Chile, Legal Publishing.

Vilajosana, J. M. (2012). Precondiciones para el análisis del conflicto entre Tribunal Constitucional y Parlamento Isonomía (36) pp. 90-116.

WALdRon, Jeremy (2005). Derecho y desacuerdos. Trad. J. L. MARTí y Á. Quiroga. Madrid/ Barcelona, M. Pons.

Weill, Rivka (2012). Hybrid Constitutionalism: The Israeli Case for Judicial Review and Why We Should Care. Berkeley Journal of International Law (30/2) pp. 349-411.

WeILl, Rivka (2014). The New Commonwealth Model of Constitutionalism Notwithstanding: On Judicial Review and Constitution-Making. The American Journal of Comparative Law (62) pp. 127-169.

Wellmer, A. (2000). Hannah Arendt sobre el juicio: la doctrina no escrita de la razón. En: F. BIRULÉs, ed. Hannah Arendt. El orgullo de pensar. Trad. J. Calvo. Barcelona, Gedisa, pp. 259-280.

WRÓBLEWSKI, JERZY (1988). Constitución y teoría general de la interpretación jurídica. Trad. A. Azurza. Madrid, Civitas.

ZÚÑIGA, F., coord. (2014). Nueva constitución y momento constitucional. Visiones, antecedentes y debates. Santiago de Chile, Legal Publishing/Thomson Reuters. 


\section{Jurisprudencia citada}

Sentencia del Tribunal Constitucional, Rol n. ${ }^{\circ}$ 146-1992, de 24 de abril de 1992 (inconstitucionalidad del decreto supremo del Ministerio de Obras Públicas n. ${ }^{\circ} 357$, publicado en el Diario Oficial de 19 de febrero de 1992, que prohibía la colocación de carteles, avisos de propaganda o cualquiera otra forma de anuncios comerciales en los caminos públicos del país).

Sentencia del Tribunal Constitucional, Rol n. ${ }^{\circ}$ 534-2006, de 21 de agosto de 2006 (inconstitucionalidad del artículo 183 ter de un proyecto de ley que, regulando el trabajo en régimen de subcontratación, introducía un nuevo concepto de empresa en el actual artículo 3 . $^{\circ}$ del Código del Trabajo, eliminando de tal concepto la exigencia de que la empresa haya de tener una "identidad legal determinada").

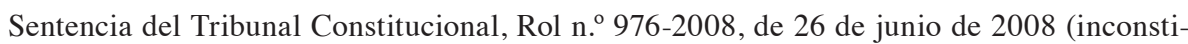
tucionalidad del artículo $38 \mathrm{ter}$ de la Ley de Isapres por vulnerar los artículos constitucionales 19 n. ${ }^{\circ}$ 2, sobre discriminación arbitraria, y n. ${ }^{\circ}$ 9, sobre la libertad de elección de sistema de salud).

Sentencia del Tribunal Constitucional, Rol n. ${ }^{\circ}$ 1710-2010, de 6 de agosto de 2010 (inconstitucionalidad de los numerales 1, 2, 3 y 4 del inciso $3 .^{\circ}$ del artículo 38 ter de la Ley de Isapres fundada en la afectación de derechos fundamentales como el de igualdad ante la ley, el de protección de la salud y el derecho a la seguridad social). 